\title{
Estudios
}

\section{APROXIMACIONES A LA SUBJETIVIDAD CANÓNICA DE LA FAMILIA}

Fecha de recepción: 17 de septiembre de 2020

Fecha de aceptación: 7 de octubre de 2020

RESUMEN: La doctrina del magisterio sobre la familia es muy abundante, mientras existen muchas lagunas en la disciplina canónica que ensombrecen su consideración real como sujeto de derechos en la Iglesia. Esta reflexión pretende proponer caminos para superar ese desfase, aclarando la incidencia jurídica de la doctrina del magisterio, tanto en la interpretación de las normas vigentes como en la integración posible de sus lagunas. La exhortación Amoris laetitia, así como los textos del reciente camino sinodal sobre el tema, son las fuentes principales de la aproximación que se propone.

PALABRAS CLAVE: derechos de la familia; Norma missionis; tutela de la familia; ministerio de la familia.

\section{Approaches to the Canonical Subjectivity of the Family}

ABSTRACT: The doctrine of the Magisterium on the family is very abundant, while there are many gaps in canonical discipline that overshadow its real consideration as a subject of rights in the Church. This reflection aims to propose ways to overcome this gap, clarifying the juridical impact of the doctrine of the magisterium, both in the interpretation of the norms in force and in the possible integration of its gaps. The exhortation Amoris laetitia, as well as the texts of the recent synodal path on the topic, are the main sources of the approach to the theme.

KEY WORDS: family rights; Norma missionis; protection of the family; family mission.

* Decano del Pontificio Instituto Teológico Juan Pablo II: mjconde@ediurcla.it; ORCID: https://orcid.org/0000-0001-7979-0671 


\section{INTRODUCCIÓN: SUBJETIVIDAD JURÍDICA Y SUBJETIVIDAD CANÓNICA}

El concepto de subjetividad jurídica hace referencia a la condición con la que se expresa la relevancia que una determinada realidad (persona física, jurídica, institución, entidad) posee con respecto a la tutela que le corresponde asegurar y organizar al Derecho, como dimensión de la experiencia humana. Si se pasa del ámbito abstracto del Derecho, con mayúsculas, al terreno concreto de los ordenamientos jurídicos, poseer subjetividad jurídica significa tener la suficiente aptitud como para que las normas positivas que rigen en una colectividad reconozcan o atribuyan la titularidad de determinados derechos y, a su vez, asignen ciertos deberes exigibles al sujeto en cuestión ${ }^{1}$.

El citado reflejo en normas positivas precisas y seguras de los derechos y deberes que quepa afirmar como pertenecientes a quienes poseen subjetividad jurídica, en el caso del derecho canónico necesita ser matizado, teniendo en cuenta que se trata de un ordenamiento cuyos contenidos exigibles, tal vez con mayor claridad e intensidad que en otros ordenamientos, no cabe reducirlos solo a los que resulten formalmente recogidos en las fuentes normativas, legislativas o consuetudinarias, de su derecho ${ }^{2}$. En efecto, la dimensión jurídica de la Iglesia tiene su razón de ser más profunda en el mandato de evangelizar (la Norma missionis) ${ }^{3}$, desde el que se enriquece la connatural exigencia de organización, de protección y de promoción de relaciones adecuadas entre los discípulos de Jesús, fortaleciendo además la fidelidad a su mensaje y consolidando, con la ayuda de una disciplina, la progresiva mejor comprensión de sus exigencias al hilo de las nuevas relaciones surgidas en la misión, también

1 Aunque en castellano el concepto más usado es el de «personalidad jurídica», el término «subjetividad jurídica» aparece en el Diccionario panhispánico del español jurídico, 2020, para referirse a la que se posee en ámbito internacional.

${ }^{2}$ La necesidad de regulación formal de los derechos subjetivos, aunque con métodos y márgenes diferentes, es fenómeno común a los ordenamientos de Common Law y de Civil Law. En el derecho canónico las fuentes normativas de carácter general son la ley (cc. 7-22) y la costumbre (cc. 23-28), junto con los decretos generales legislativos (asimilados a la ley, c. 29) y las instrucciones (dadas para aplicar las leyes, c. 34$)$.

3 Paolo Gherri (ed.). Diritto canonico e pastorale: la norma missionis, Atti della Giornata canonistica interdisciplinare. Città del Vaticano: Lateran University Press, 2020. 
con la realidad externa a la comunidad, principal destinataria de la misma. Estos planteamientos responden a la necesidad de asumir, también en el derecho eclesial, el principio según el cual Ius sequitur vitam ${ }^{4}$. A la luz de ellos, la cuestión de la subjetividad canónica no puede estudiarse permaneciendo en el terreno del mero derecho positivo, sino que debe tenerse en cuenta la incidencia que tiene en este tema, como en cualquier otro, el fundamento misionero del derecho de la Iglesia ${ }^{5}$.

La promoción de una buena experiencia de familia, también con normas eclesiales idóneas y eficaces, es un punto central de la evangelización y, por ende, del ordenamiento canónico. Referirse a la familia desde su subjetividad canónica implica afirmar que la familia no es solo objeto de la evangelización, sino también sujeto muy relevante de la misma en su condición de Iglesia doméstica ${ }^{6}$. Aun así, las concreciones de dicha subjetividad tienen un reflejo tal vez demasiado pobre en las normas positivas canónicas, cuyo objeto resulta limitado en su orientación y en su contenido, centrado casi todo en la dimensión educativa. Otros aspectos muy recalcados por el magisterio constante de la Iglesia no están suficientemente traducidos en la disciplina, por lo que no deja de señalarse la desproporción entre el volumen elevado del magisterio eclesial sobre la familia y la casi absoluta inexistencia de lo que podría denominarse "derecho canónico de la familia», cuya suerte es, pues, la misma que acontece en el terreno de la teología: abundancia sobre el matrimonio frente a muchas lagunas sobre la familia.

Esa situación merece ser superada. Cabe afirmar que en las reflexiones sinodales de 2014 y 2015 hay una demanda implícita de ampliación en la comprensión de dicha subjetividad desde otros retos que caracterizan la hora presente del mundo y de la Iglesia, permitiendo diseñar desde ellos la renovación de la pastoral familiar, así como lo que podría considerarse «ministerio específico de la familia»: un ministerio que va más allá de las paredes del hogar y que se proyecta en favor de

4 Manuel J. Arroba Conde. "Basi ecclesiologiche e limiti intrinseci di una rinnovata produzione normativa locale". Folia Canonica 10 (2007): 153-166.

5 Para una presentación de todos los sectores del ordenamiento canónico desde su fundamento misionero, Manuel Jesús Arroba Conde y Michele Riondino. Introduzione al Diritto canonico. 3. ${ }^{\text {a }}$ ed. Milano: Mondadori Education, 2019.

6 Lumen Gentium 11 y Apostolicam actuositatem 11; Cardenal Carlos Osoro. La familia, Iglesia doméstica. Una propuesta pastoral. 2. ${ }^{a}$ ed. Madrid: PPC, 2019. 
toda la comunidad, tanto eclesial como extraeclesial ${ }^{7}$. La exhortación postsinodal Amoris laetitia (AL) sobre todo en sus capítulos VI y VIII, se hace eco de las indicaciones sinodales sobre el ministerio en favor de la familia y desde la familia, por lo que se debe considerar principal punto de referencia al aproximarse al tema que nos ocupa. Objeto de esta reflexión es proponer pistas que, a la luz del más reciente magisterio papal y sinodal sobre la familia, contribuyan a la mejor interpretación y consolidación de su subjetividad canónica y, con ello, favorezcan su aplicación.

\section{PERSPECTIVA INSTITUCIONAL: LA FAMILIA COMO SUJETO DE DERECHO}

Para alcanzar el objetivo propuesto hay que superar el planteamiento que subyace a los cc. 96 y 113, en los que la subjetividad jurídica en el derecho canónico, como en la mayor parte de ordenamientos, parece referible solo a personas físicas ${ }^{8} \mathrm{o}$ a personas jurídicas erigidas y reconocidas formalmente como tales ${ }^{9}$. Tal superación es posible si se asume un planteamiento institucional, donde el principal esfuerzo consista en no disolver la tutela de los bienes jurídicos que se considere necesario asegurar a la familia, así como la asignación de sus responsabilidades,

7 M. J. Arroba Conde. "La recente esperienza sinodale in prospettiva canonica". Commentarium pro Religiosis et Missionariis 96 (2015): 263-286. En el documento conclusivo de la asamblea extraordinaria del 2014 (en adelante indicado como Relatio Synodi) el objetivo se expresa en el n. 37 al referirse a la «necesidad de una renovación radical de la pastoral a la luz del Evangelio de la familia»; en el de la asamblea del 2015 (en adelante indicado como Relatio finalis) puede considerarse expresada la exigencia de empezar de nuevo desde la familia en el n. 56, donde se afirma que el Evangelio de la familia es la «respuesta a las esperanzas más profundas de la persona».

8 El c. 96 establece que por el bautismo el hombre queda incorporado a la Iglesia de Cristo y se constituye persona en ella con los deberes y derechos que sean propios de los cristianos, teniendo en cuenta la condición de cada uno, en cuanto estén en la comunión eclesiástica y no lo impida una sanción legítimamente impuesta.

9 El c. 113 §2 establece que, en la Iglesia, además de personas físicas, hay también personas jurídicas, que son sujetos, ante el derecho canónico, de las obligaciones y derechos congruentes con su propia índole. 
en los bienes y responsabilidades que el derecho establece para cada uno de sus componentes.

Se trata pues de afianzar la consideración de la familia en sí misma como sujeto de derechos que, aun sin prescindir de ellos, enriquecen y van más allá de los derechos de sus miembros o que, al menos, no sería adecuado reconducir a ellos en cuanto derechos individuales; estos últimos, por otra parte, tienen contenido diversificado, según el rol de cada cual dentro de la vida familiar. Como veremos seguidamente, la mayoría de las normas relacionadas con nuestro tema están formuladas en el Código de Derecho Canónico desde una perspectiva personal, regulando algunos derechos y deberes de los cónyuges entre sí, otros (la mayoría) de los padres para con los hijos (sobre todo en cuanto al munus docendi y al munus santificandi), con sus correspondientes implícitos deberes y derechos de los hijos para con sus padres, junto a ciertas disposiciones sobre relaciones jurídicas entre personas unidas por lazos, fuera del núcleo familiar ${ }^{10}$. En modo similar proceden los ordenamientos jurídicos nacionales, a quien pertenece la competencia para regular el tema, incluyendo en su normativa más estable y de mayor rango el «derecho de familia», cuyo objeto son más bien las relaciones jurídicas entre sus miembros: matrimonio, relaciones conyugales, filiación, potestad parental, custodia, sucesión, etc. ${ }^{11}$.

Aun así, hay algunas pistas sobre la posibilidad de afirmar la subjetividad jurídica de la familia en el derecho secular, tanto en el ámbito internacional como en otras fuentes de los derechos nacionales. A ellas se añade, como fuente eclesial de gran envergadura, la Carta de los derechos de la familia, preparada y presentada por el ya extinguido Pontificio Consejo para la Familia, donde se manifiesta la apuesta eclesial tal vez más

${ }^{10}$ Se trata de las normas sobre los impedimentos matrimoniales de consanguinidad (c. 1091), afinidad (c. 1092), pública honestidad (c. 1093) y parentesco legal (c. 1094).

${ }_{11}$ En España el derecho de familia se regula desde antaño en el Código de derecho civil, en sus partes I (sobre los aspectos individuales) y IV (sobre los aspectos económicos). Aunque el sector del derecho civil pertenece al derecho privado, no han faltado voces en la doctrina (como la del italiano Antonio Cicu) que ya desde finales del siglo XIX venían reclamando la mayor pertinencia de la consideración del derecho de familia como parte del derecho público, arguyendo la naturaleza supraindividual de algunos de sus contenidos más importantes. 
decidida por favorecer que se asuma en el terreno mismo del derecho el planteamiento institucional al que nos estamos refiriendo ${ }^{12}$.

La fuente de nivel internacional de mayor interés es el art. 16 de la Declaración de Derechos Humanos proclamada por la ONU en 1948 donde, tras reconocer el derecho de todos los hombres y mujeres a casarse y fundar una familia, sin restricciones por motivos de raza, nacionalidad o religión, gozando además de iguales derechos en el matrimonio, y tras establecer que el matrimonio puede contraerse solo mediante libre y pleno consentimiento de los esposos, en el tercer párrafo se afirma que «la familia es el elemento natural y fundamental de la sociedad y tiene derecho a la protección de la sociedad y del Estado» ${ }^{13}$. Es la familia misma el sujeto al que se le reconoce el derecho a ser protegido; tal tutela cabe referirla sobre todo a las leyes internas que emanan las instituciones públicas de cada Estado, así como a los aspectos disciplinares remitidos a la libre iniciativa de los agentes sociales; ambos tipos de normativa han de ser compatibles con el derecho a la protección, reconocido a la familia, del mismo modo que con el resto de derechos humanos de la Declaración universal. Esta disposición se reitera en el Pacto internacional sobre los derechos civiles y políticos de 1966 (art. 23 §1) ${ }^{14}$, así como en otras declaraciones internacionales de derechos humanos de carácter regional ${ }^{15}$.

En cuanto a los derechos nacionales, la incidencia de la Declaración Universal de Derechos Humanos en el "derecho de familia», al tener por objeto las relaciones entre sus miembros, recae sobre todo en las materias más expuestas a generar situaciones de desigualdad entre cónyuges, de desprotección de los hijos, de ejercicio inadecuado de la autoridad

12 Su título completo es Carta de los derechos de la familia presentada por la Santa Sede a todas las personas, instituciones y autoridades interesadas en la misión de la familia en el mundo contemporáneo, 22.10.1983, (Osservatore Romano, 25 noviembre 1983).

13 Declaración Universal de los Derechos Humanos, ODI https://www.ohchr.org/ EN/UDHR/Documents/UDHR_Translations/spn.pdf

${ }_{14}$ Pacto internacional sobre los derechos civiles y politicos, ODI https://www.ohchr. $\mathrm{org} / \mathrm{sp} /$ professionalinterest/pages/ccpr.aspx

15 Es el caso de la Convención interamericana de 1969 (https://www.oas.org/dil/ esp/tratados_b-32_convencion_americana_sobre_derechos_humanos.htm), de la Carta africana de los derechos del hombre y de los pueblos de 1981 (http://www.derechoshumanos.net/normativa/normas/africa/CAFDH/1981-CAFDH.htm) y de la Carta árabe de los derechos humanos de 2004 (https://www.acihl.org/res/documents/CARTA-\%C3\%81RABE-DE-DERECHOS-HUMANOS.2004.pdf). 
de los padres sobre ellos, de discriminación entre los componentes de la familia... A estas materias, en tiempos recientes, se suman otras relacionadas con la prevalencia que debe asegurarse en las legislaciones nacionales a la tutela del «interés superior del menor ${ }^{16}$, sobre todo en caso de separación y divorcio. En este específico sector del derecho de familia tiene pues poca cabida la consideración de la familia como sujeto de derechos y beneficiaria del derecho a ser protegida; no puede decirse lo mismo del sector más vivo y dinámico de los derechos nacionales, esto es, las disposiciones que, según las formas establecidas en cada Estado, se emanan constantemente, sea por parte de las instituciones públicas, sea por los agentes sociales en su propio sector, para salir al paso de las exigencias cambiantes que demanda la realidad social. En este amplio y más dinámico sector legislativo y disciplinar es frecuente que la familia sea tomada como punto de referencia a la hora de regular algunas materias ${ }^{17}$, si bien tal referencia no obedece a un modelo único de familia, cuestión sobre la que se asiste a un pluralismo legislativo cada vez más acentuado ${ }^{18}$. Aunque dicho pluralismo pueda plantear nuevas problemáticas y dejar sin resolver con suficiente certeza

${ }^{16}$ Cf. M. Riondino. "The right to education: a fundamental and universal right". Jus 63 (2016): 287-300; R. C. Akhtar \& C. Nyamutata. International Child Law. London and New York: Routledge, 2020, 204-208; E. Verhellen. Convention on the Rights of the Child. Background, motivations, strategies, main themes. $4^{\text {th }}$ ed. Antwerpen: Garant, 2006, 11-18.

17 Piénsese en la emergencia sanitaria provocada por la COVID-19, frente a la cual las instituciones y los agentes sociales han reaccionado con medidas orientadas a favorecer a las familias, tomando en consideración su situación efectiva; entre ellas, por incluir entre los requisitos la precariedad de la renta familiar, merecen señalarse la moratoria sectorial de hipoteca y crédito al consumo, o la moratoria de préstamos hipotecarios, no hipotecarios y tarjetas de crédito, concordadas por la Asociación Española de Banca, para dar curso a las directrices del Gobierno en los Decretos leyes 8 y 11 de 2020. Entre las materias de competencia de las instituciones públicas pueden considerarse sensibles a las nuevas exigencias de protección de la familia, a nivel nacional, el Real Decreto 613/2007 por el que se crean y regulan el Consejo y el Observatorio estatal de familia; a nivel nacional y autonómico, la ley de dependencia, que en su desarrollo territorial incluye casos en los que se regulan los derechos reconocidos cuando los cuidados se prestan en el entorno familiar.

18 No le toca al derecho internacional sino a las leyes internas de cada Estado, establecer el modelo o modelos. En el caso de España el concepto que se maneja actualmente es el de «unidad familiar». 
algunos aspectos dignos de protección, lo que ahora interesa afirmar es el incremento de la referencia a la familia como sujeto de derechos.

En esa óptica se mueve sin titubeos la Carta de los derechos de la familia ${ }^{19}$ redactada por el Pontificio Consejo para la Familia ${ }^{20}$, hoy desaparecido e integrado en el Dicasterio para los laicos, la familia y la vida ${ }^{21}$. Toda ella, como se afirma expresamente en su introducción, está concebida con la finalidad de presentar «una formulación, lo más completa y ordenada posible, de los derechos fundamentales inherentes a esta sociedad natural y universal que es la familia», partiendo del presupuesto de que «la sociedad está llamada a defender estos derechos contra toda violación, a respetarlos y a promoverlos en la integridad de su contenido». Resulta evidente la cercanía en el lenguaje de estas premisas de la Carta de los derechos de la familia con el del art. 16 de la Declaración Universal de los Derechos Humanos; la correspondencia entre ambos textos se hace notar en tres elementos: en el reconocimiento explícito de la institución familiar como sujeto de derechos; en la justificación de tal reconocimiento por su condición de grupo natural y universal irrepetible; y en hacer consistir el contenido principal de sus derechos en la protección que merece por parte de la sociedad. La aportación original de este documento no reside propiamente en los contenidos que se proponen como derechos, enunciándolos en sus doce artículos ${ }^{22}$, sino en la pretensión de presentarlos de manera más completa, ordenada y adecuada en su formulación, con una mejor definición de los mismos. Es cierto que, en algunos de sus artículos,

${ }^{19}$ La Carta está compuesta por una Introducción, seguida de un preámbulo formado por trece considerandos (expuestos siguiendo el orden de las letras del alfabeto), los doce artículos y un anexo con sus fuentes. D. Martin. "La Carta dei diritti della Famiglia; le sue origini e la sua originalità". En La famiglia e $i$ suoi diritti nella comunità civile e religiosa, 99-107. Roma: Libreria Editrice Vaticana - Libreria Editrice Lateranense, 1987.

20 El Pontificio Consejo para la Familia fue el organismo a través del cual la Santa Sede, instada por la asamblea del Sínodo de Obispos de 1980 para tratar el tema de la familia (en su proposición 42) y, sucesivamente, por el papa Juan Pablo II (en la exhortación postsinodal Familiaris Consortio, 46), cumplió el mandato de redactar un documento sobre los derechos de la familia para ser presentado a las autoridades y organismos interesados.

21 Francisco, Litterae motu proprio datae Sedula Mater.

22 En la introducción se advierte que se trata de derechos, en su mayoría, ya presentes en documentos y legislaciones de los Estados, de la comunidad internacional y de la misma Iglesia. De los mismos se da cuenta en el anexo. 
los contenidos de la Carta hacen referencia a derechos diferenciados de los miembros de la familia, como ocurre con los sectores más estáticos de las legislaciones seculares ${ }^{23}$ y con la legislación canónica. Pero en otra parte muy consistente de artículos sus contenidos se formulan desde una perspectiva institucional e innovadora ${ }^{24}$. En el primer considerando del preámbulo, se afronta el fundamento de esta perspectiva: «los derechos de la persona, aunque expresados como derechos del individuo, tienen una dimensión fundamentalmente social, que tiene su expresión innata y vital en la familia»; de esa convicción parten ulteriores justificaciones, expresadas en algunos de los sucesivos considerandos, en los que se aboga por consolidar el reconocimiento de la familia como sujeto de «derechos que son propios e inalienables»: por ser anterior al Estado y a cualquier otra comunidad; por ser lugar de experiencia intergeneracional que permite el crecimiento en aquella sabiduría que consiente armonizar los derechos del individuo con el bien de la sociedad; por tener una función específica en la consecución del bien de las personas y de toda la humanidad; por ser en ocasiones objeto de diversas formas de desamparo que no le permiten cumplir su función con dignidad.

\section{EL CONTENIDO LIMITADO DE LOS CÁNONES}

Esa perspectiva, en lo que concierne a la formulación de las normas positivas, apenas tiene un reflejo en el Código de Derecho Canónico de 1983, a pesar de que en la introducción de la Carta se advierta que la

${ }^{23}$ Se formulan en clave de derechos individuales los recogidos en los arts. 1-5 en los que se toma en cuenta la condición de personas, de futuros esposos, de padres y de hijo nasciturus, menor o con discapacidad. Representan una excepción los arts. $3 \mathrm{c}$ (que formula la asistencia como un derecho de la familia) y $5 \mathrm{f}$ (sobre el derecho de la familia a ser protegida en los medios de comunicación). Entre las cuestiones más espinosas se encuentra la subjetividad jurídica del nasciturus, G. Ballarani. "Nascituro (soggettività del)". En Enciclopedia de la bioética e scienza giuridica, dirigido por Sgreccia y Tarantino, vol. IX, 136ss. Napoli, E.S.I., 2015.

${ }^{24}$ Además de los referidos en la nota anterior, los contemplados en los arts. 6-12 se atribuyen directamente a la familia: a la promoción de su vida, de su independencia, de su estabilidad por parte de las autoridades públicas; a la libertad religiosa; a ejercer su función política y social; a asociarse; a una adecuada política familiar en materia de economía, de seguridad social, de cuidados en la ancianidad, de regulación penitenciaria, de vivienda y de reunificación familiar en caso de familias de migrantes. 
misma va dirigida como «una llamada particular» también a «todas las instituciones de la Iglesia» con el fin de afianzar en ellas la exigencia de dar testimonio de la propia cultura sobre la «misión irremplazable de la familia». Esa poca incidencia en la renovación de la ley universal de la Iglesia sobre la subjetividad jurídica de la familia no se corresponde con el contenido del último de los considerandos del preámbulo, donde se afirma la conciencia de que «el bien de las personas, de la sociedad y de la Iglesia pasa por la familia». Llama la atención esta circunstancia si se tiene en cuenta que ambos documentos fueron contemporáneos en buena parte de sus fases de redacción ${ }^{25}$.

Es conocida la discusión a la que se asistió durante los trabajos de redacción del código respecto a la inclusión en él de un derecho de familia canónico, donde acabaron imponiéndose razones poco convincentes para descartarlo ${ }^{26}$. El resultado es un cierto progreso en el derecho codificado respecto a los contenidos y, al mismo tiempo, el mantenimiento del planteamiento sobre el tema que resulta más tradicional y habitual en otras legislaciones, con los límites y lagunas que conlleva el hecho de prescindir casi por completo de una perspectiva institucional y de privilegiar la perspectiva individual al formular las disposiciones ${ }^{27}$. Basta echar una ojeada a la mayor parte de ellas para percatarse de esa preferencia por el planteamiento tradicional.

Muchas de las normas se refieren a temas relacionados con la función educativa sobre la que, aunque en la conciencia social no se dude del papel insustituible de la familia, las normas se formulan desde las atribuciones y responsabilidades de los padres. Así, en el c. 226 §2, en la sección sobre los derechos de los fieles laicos, se establece el deber y derecho de los padres a educar a los hijos por haberles transmitido la vida. En la sección sobre la formación catequética el c. 774 §2 afirma que la

${ }^{25}$ La Carta de los derechos de la familia fue elaborada entre 1981 y 1982; en la elaboración del Código esos años fueron los de la redacción del último esquema, sometido al papa para su revisión final y sucesiva promulgación.

${ }^{26}$ Se argumentó, junto la escasa competencia de la jurisdicción eclesiástica sobre temas de derecho de familia distintos del matrimonio, que el derecho de familia no respondería ni a la índole ni a la sistemática del Código. M. Riondino. "La tutela dei minori nell'ordinamento canonico". En La Chiesa tra economia e famiglia, dirigido por G. Dammacco, 181-193. Bari: Cacucci, 2015.

27 E. Vitali. "Riflessioni sui rapporti familiari nell'esperienza giuridica ecclesiale". Il Diritto ecclesiastico 116 (2005): 409-430. 
obligación de formar en la fe y en la praxis cristiana es tarea de los padres, antes que de ningún otro, especificando que se trata de formación a través de la palabra y el ejemplo. En la sección sobre la educación católica se dan varias disposiciones: el c. 793 §1 reitera el contenido del c. $226 \$ 2$ pero añade la elección de los medios e instituciones que mejor aseguren la educación católica de los hijos como reflejo concreto de sus derechos y deberes en la educación de los hijos; el c. 796 hace referencia a la estima y cooperación que los padres han de prestar a la escuela en la que se educan sus hijos; el c. 797, aplicando a la escuela el derecho de elección que pertenece a los padres en materia educativa, indica como deber - no solo de ellos sino de todos los fieles- la solicitud por la que dicha libertad de los padres sea garantizada y tutelada con ayudas económicas justas; el c. 798 establece el deber de los padres de confiar la educación de sus hijos a escuelas católicas o, al menos, de procurar que fuera de las escuelas se organice la educación católica; el c. 799 trata del deber de los fieles por procurar una legislación educativa que incluya la educación religiosa y moral de los jóvenes según la conciencia de sus pa$\mathrm{dres}^{28}$. En el sector del derecho matrimonial se reiteran las atribuciones y responsabilidades educativas de los padres, especificando que se trata de deber gravísimo y que abarca el cuidado físico junto con la educación social, cultural, moral y religiosa.

Otras normas tienen por objeto el derecho sacramental. Además de las que tratan del matrimonio (sobre las que volveremos después), merecen mención el c. $835 \S 4$, que califica como participación «peculiar» en la función de santificar la que corresponde a los padres «impregnando de espíritu cristiano la vida conyugal y procurando la educación cristiana de

${ }^{28}$ Sobre la educación religiosa del menor, M. R. Garcia Vilardell. "La libertad de creencias del menor y las potestades educativas paternas: la cuestión del derecho de los padres a la formación religiosa y moral de sus hijos". Revista española de derecho canónico, 66 (2009): 331-351; M. T. Cerdà Donat. "Educación católica y sociedad civil". Anuario de Derecho Canónico 5 (2016): 165-187; M. Miele. "Educazione religiosa del minore". En Scuola, Famiglia e Minori, dirigido por M. Cerato y F. Turlon, 401-425. Pisa: Pacini Giuridica, 2018; F. De Angelis. L'educazione del minore e la libertà religiosa. Città del Vaticano: Lateran University Press, 2018, 65-73; M. Riondino. "L'interesse del minore come legittimazione e limite dell'ordinamento in materia religiosa". En Legittimazione e limiti degli ordinameni giuridici, dirigido por G. L. Falchi y A. Iaccarino, 623-633. Città del Vaticano: Lateran University Press, 2012. 
sus hijos». Refiriéndose a la preparación para la recepción del bautismo de sus hijos, el c. 851, 2 formula implícitamente el derecho de los padres a ser instruidos sobre su significado y a ser sostenidos en la práctica de la oración en común por los párrocos o por otros agentes pastorales, a través de visitas y de reuniones entre varias familias. A esta norma corresponde el c. 867, que establece el deber de los padres de bautizar pronto a sus hijos y de acudir al párroco para pedirlo y para prepararse debidamente; en el c. 868 se establece para la licitud del bautismo el consentimiento de los padres, o al menos de uno de ellos, o de quienes hacen sus veces. En términos parecidos se expresa el c. 914 indicando el deber de los padres de asegurar que sus hijos se preparen para la recepción de la eucaristía. En el sector del derecho penal merece ser destacado el c. 1366 donde se protege la obligación de bautizar a los hijos y de asegurar su educación católica, con la previsión de una censura o de otra pena justa para aquellos padres que entregan a sus hijos para que sean bautizados o educados en una religión acatólica ${ }^{29}$.

Son una excepción a este planteamiento individual dos disposiciones formuladas en perspectiva institucional. La primera es el c. 1152, donde se reconoce la subjetividad canónica de la familia con la voluntad de proteger el bien de la misma, animando al perdón del cónyuge en caso de adulterio, sin ejercer el derecho personal a la separación conyugal. La segunda es el c. $226 \S 1$, donde dicha subjetividad se formula en el ámbito de los deberes y consiste en la obligación de quienes están llamados al estado de vida conyugal a edificar el Pueblo de Dios a través del matrimonio y la familia. A esta última disposición cabe asimilar el derecho de asociación, reconocido en la Iglesia, entre otras cosas, para informar de espíritu cristiano el orden temporal (c. 298 §1); el c. 327 anima a los fieles laicos al aprecio de las asociaciones que se proponen dicho fin; cabe encontrar en ello una implícita referencia al derecho de asociación como derecho especial de la familia, vista la relación entre la información del orden temporal de espíritu cristiano y la edificación del Pueblo de Dios, sobre la que la referencia a la familia, en la norma del código, es explícita.

${ }^{29}$ Sobre estos aspectos, G. Degiorgi. I minori nella legislazione della Chiesa. Venezia: Marcianum Press, 2015, 129-144. 


\section{INCIDENCIA JURÍDICA DEL MAGISTERIO: LAS LAGUNAS DE LA LEY Y LA NORMA MISSIONIS}

La acentuada diferencia de perspectiva respecto a la temática familiar entre la mayor parte de los cánones y la Carta de los derechos de la familia pudiera considerarse justificada en razón de su distinta naturaleza. En la redacción de los cánones, a pesar de su fundamento doctrinal, se intentó evitar que pudiera acabar difuminada su naturaleza exquisitamente jurídica ${ }^{30}$; en el caso de la Carta, al contrario, al tratar de su naturaleza, en la introducción se hace referencia a una pluralidad de elementos, pero se descarta expresamente que toda ella pueda considerarse formada por preceptos jurídicos. Cabe pues calificar la Carta, aun con matices, como documento cuyo contenido en su conjunto es doctrina magisterial ${ }^{31}$. Ello sugiere no dejar de lado, entre los elementos a tener en cuenta en esta reflexión, el tema de la relación existente entre el derecho canónico y el progreso en la enseñanza del magisterio, intentando aclararlo optando por un punto de vista preciso sobre ello.

Se caería en un riesgo similar al positivismo si se tuvieran por únicos contenidos del derecho canónico las normas del código junto a otras posibles determinaciones o declaraciones externas al código, con tal de que hayan sido formalmente promulgadas como disciplina. En esa orientación, las enseñanzas magisteriales no tendrían cabida en el ordenamiento canónico. Dicha visión hunde quizás sus raíces en la idea de que el magisterio afecta solo a la dimensión moral y a las orientaciones éticas y que, por tanto, no se refiere a materias jurídicamente protegidas, al menos hasta que una enseñanza magisterial no se convierta, a su vez, en disciplina clara exigible.

En realidad, no es correcto identificar el concepto de derecho canónico con sus normas. El sistema jurídico de la Iglesia tiene otras fuentes además de las normas promulgadas formalmente dentro o fuera del código. Una de esas fuentes es la doctrina y, principalmente, la doctrina del magisterio,

${ }^{30}$ A ello se refería el primer principio de revisión del Código indicado por el Sínodo de Obispos de 1967.

${ }^{31}$ En la introducción de la Carta se afirma: «los derechos que aquí se proponen han de ser tomados según el carácter específico de una Carta. En algunos casos, conllevan normas propiamente vinculantes en el plano jurídico; en otros casos, son expresión de postulados y de principios fundamentales para la elaboración de la legislación y desarrollo de la política familiar. En todo caso, constituyen una llamada profética en favor de la institución familiar que debe ser respetada y defendida contra toda agresión». 
que ocupa su lugar en el sistema del derecho canónico de dos maneras: ante todo, como un criterio para comprender y aplicar las normas mismas (c. 17) ${ }^{32}$; en segundo lugar, como un principio a partir del cual adoptar directrices sobre cómo proceder en los casos en que no exista norma explícita (c. 19) ${ }^{33}$. La incidencia canónica de las enseñanzas magisteriales es más clara en el caso de la doctrina social de la Iglesia, porque su objeto es más cercano a la organización jurídica y porque, en relación con aspectos sociales, el magisterio se enfrenta a menudo a nuevos problemas o, por lo menos, debe explicar problemas permanentes de una nueva manera.

Esta forma de entender el derecho canónico es más abundante entre los autores que encuentran su fundamento en la Norma Missionis ${ }^{34}$. Este concepto se refiere al mandato misionero final de Jesús, que encontramos en las últimas palabras del Evangelio de $\mathrm{Mateo}^{35}$. No podemos explicar detalladamente la teoría y metodología para el estudio del derecho canónico que se propone en esta orientación ${ }^{36}$. Para el tema que nos ocupa, es suficiente mencionar que la Norma Missionis es la única ley verdadera, la única norma que puede considerarse siempre inmutable y vinculante, sin ninguna excepción; otras disposiciones canónicas están sujetas a evolución, según las necesidades que puedan brotar de las exigencias mismas de la misión ${ }^{37}$.

${ }^{32}$ Entre los criterios de interpretación del c. 17 se debe considerar incluida la doctrina del magisterio, como se deduce de la constitución de promulgación Sacra Disciplinae Leges al señalar las enseñanzas conciliares como "contexto» de las normas. La mens legislatoris hace referencia directa a quien emana la norma pero la autoría papal de las leyes universales vincula la comprensión de sus contenidos al magisterio pontificio vigente en cada momento en que hayan de aplicarse.

33 El c. 19 incluye la doctrina como criterio para resolver casos de lacuna legis al tratar las causas, pero ello no impide considerar que deba recurrirse a ella en circunstancias en las que sea útil establecer una disciplina general.

34 Paolo Gherri. "Identità ecclesiale e Norma Missionis". Apollinaris 91 (2018): 505-544, donde se indican los autores de esta corriente y sus principales textos.

35 Mt 28,19: «Id, pues, y haced discípulos a todos los pueblos, bautizándolos en el nombre del Padre y del Hijo y del Espíritu Santo; enseñándoles a guardar todo lo que os he mandado".

${ }^{36}$ En cuanto a las dimensiones y método que caracterizan esta orientación en el estudio del derecho canónico, Manuel Jesús Arroba Conde. "Missione ecclesiale e pastorale giudiziale”. Apollinaris 91 (2018): 405-426. Relacionado con ello, Arroba Conde. "Il metodo dell'utrumque ius". Apollinaris 90 (2017): 265-272.

37 Calificar como Norma Missionis el mandato misional de Jesús no debe comportar entenderlo solo desde su naturaleza prescriptiva, como oportunamente se 
Esto significa que, para la vida de la Iglesia, el derecho canónico es un factor importante no solo para preservar la integridad del mensaje evangélico ${ }^{38}$, sino también como factor para promover una nueva comprensión de sus contenidos a la luz del nuevo contexto de la misión, según un principio jurídico: ius sequitur vitam. Que el derecho deba estar al servicio de la vida es la razón por la cual la disciplina canónica debe siempre ser interpretada desde las exigencias de actualización que derivan de la misión, amén de poder ser integrada y completada para permitir que la Iglesia sea testigo de su propia cultura jurídica, manteniendo los valores humanos más elevados a la luz del ideal evangélico y, al mismo tiempo, incluyendo en su propio sistema algunos caminos jurídicos nuevos creados dentro de la sociedad, si son válidos para cumplir con su misión de un modo mejor.

Este doble camino de incidencia jurídica de la doctrina del magisterio (la interpretación actualizada de las normas o la integración de posibles lagunas) es muy claro en lo que concierne a su renovada sensibilidad en materia de familia. La enseñanza sobre ello es buen ejemplo de la tarea indispensable que representa para la Iglesia el discernimiento sobre los signos de los tiempos, por medio de los cuales el Espíritu Santo habla incesantemente y guía a la misma Iglesia para que conozca mejor la verdad sobre la que está llamada a dar testimonio. Los signos de los tiempos no tienen como límite las fronteras eclesiásticas; es más, pueden ser trazados - y a menudo son trazados- partiendo de experiencias, mentalidades, reivindicaciones y esperanzas maduradas por las personas, incluso

recuerda desde la reflexión teológica: «podríamos decir que, así como el amor no es ya una prescripción, sino una respuesta al don otorgado, así también la misión no radica únicamente en el mandato expreso del Señor Jesús (Mt 28,19-20), sino también, y más profundamente, en el dinamismo mismo de la existencia cristiana. El envío misionero de los discípulos es inclusión en la vida de Dios, en su modo de darse y, por esto mismo, participación en la apertura de Dios al mundo. Como bien señala Y. Congar, en el decreto Ad gentes divinitus, se habla del envío de los discípulos de Cristo a un doble nivel: por una parte, porque pertenecen a una Iglesia que ha recibido un mandato formal de misión; por otra, porque su vida - fe, caridad, incorporación al cuerpo místico, presencia del Espíritu Santo- los incluye en una responsabilidad y los impulsa por un dinamismo interior a dar testimonio del evangelio y a dilatar el Cuerpo de Cristo en nuevas vidas personales y en nuevos espacios humanos», Samuel Sueiro. "Espiritualidad para la misión”. Estudios Eclesiásticos 95 (2020): 82-83.

38 Preservar corresponde solo a una parte del mandato de Jesús: «enseñándoles a guardar todo lo que os he mandado». 
fuera de la Iglesia católica, quizás lejos de la misma, a veces incluso en aparente hostilidad contra la Iglesia.

Justamente por la exigencia de releer el Evangelio de la familia a la luz de los signos de los tiempos, teniendo en cuenta las transformaciones que había conocido la situación de la familia desde la anterior Asamblea ordinaria del Sínodo de Obispos sobre el tema (celebrada en el año 1980), el papa Francisco convocó dos asambleas en los años 2014 y 2015, permitiendo así un tiempo prolongado de reflexión eclesial, episcopal y estrictamente sinodal, cuyas principales conclusiones bien pueden ser expresadas desde la voluntad de repensar toda la acción pastoral empezando de nuevo desde la familia ${ }^{39}$. Es cierto que, sobre las consecuencias jurídicas y canónicas de ese renovado proyecto, la experiencia sinodal fue problemática y compleja, con resultados desiguales en la primera y segunda asambleas. En la segunda, con más lucidez, esfuerzo y claridad que en la primera, se pudo evitar en mayor medida el riesgo de polarización y de tergiversación temática que, insidiosamente, pesó sobre la primera asamblea donde, tal vez por lo parciales que pudieron ser ciertas comunicaciones sacadas del aula, parecía que su objeto había sido solo el matrimonio y no la familia. La lectura del último documento de la asamblea ordinaria, sobre todo en la primera parte referida a la escucha de la familia, es prueba suficiente de una superación más decidida de este riesgo, si comparamos su contenido con el del documento sinodal conclusivo de la asamblea extraordinaria ${ }^{40}$. Dicha superación se consolida aún más en la exhortación papal sucesiva a las asambleas sinodales, donde a sus

39 En la Relatio Synodi n. 37 se afirma que el Evangelio de la familia debiera ser guía en la renovación de todos los sectores de la pastoral. En la Relatio finalis n. 56 se justifica la idea de plantear desde la familia la renovación pastoral reiterando que la familia es la respuesta a las esperanzas más profundas de las personas.

40 En la Relatio Synodi estas reflexiones estaban presentes en la primera parte que constaba de solo seis números (5-11); en la Relatio finalis la primera parte aparece mucho más rica, añadiendo a las cuestiones relativas al contexto antropológico y cultural, el contexto socioeconómico (con referencia expresa a las políticas a favor de la familia en n. 15) y un conjunto de propuestas articuladas sobre los desafíos específicos que representan las situaciones de los diversos miembros de la familia (mujeres, hombres, niños, personas con necesidades especiales, jóvenes) así como algunas de las situaciones más extremas que pesan sobre la estabilidad familiar (migraciones, nuevas pobrezas, persecuciones); también los nn. 91-92 muestran que el objeto del discernimiento sinodal era la familia y no solo el matrimonio. 
principales conclusiones y propuestas se añaden otras con un perfil más marcadamente familiar y aún más claro sobre la prioridad pastoral que, en el momento actual, debe reconocerse al seguimiento concreto de las variadas experiencias familiares, entendiéndolo como criterio imprescindible para asegurar la autenticidad al proclamar el Evangelio de la familia y como estrategia desde la que ayudar a las personas a encaminarse hacia ese ideal, suscitando confianza en él como el cumplimiento más cabal del innato "deseo de familia», concepto desde el que parte y se articula toda la enseñanza ${ }^{41}$.

En ese sentido, el magisterio más reciente sobre la familia, expresado en los textos conclusivos de las asambleas sinodales sobre el tema y en la exhortación postsinodal Amoris Laetitia, permite avanzar en la cuestión de la subjetividad canónica de la familia desde tres ámbitos derivados estrechamente de las principales pistas de acción pastoral sugeridas, que se resumen en la necesidad de establecer una adecuada relación entre la imprescindible proclamación del ideal de familia y el acercamiento a las realidades familiares. Desde ese punto de partida, un primer avance discurriría por la necesidad de proyectar la subjetividad de la familia en clave inclusiva, como de hecho permite la perspectiva individual con la que se formulan en el código algunos derechos; un segundo avance se perfila desde la correspondiente necesidad de interpretar tales derechos de las personas, sobre todo el derecho matrimonial, desde el horizonte que exige la promoción de una buena experiencia de vida en familia; por último, vistas las lagunas de la disciplina, un tercer avance reside en la conveniencia de completar, con una disciplina ágil y con los instrumentos jurídicos que mejor puedan favorecer la acción pastoral, la protección de los derechos de la familia, tanto en la atención hacia ella como en el respeto y fomento de lo que a ella pertenece como ministerio en la vida de la Iglesia y en su acción social.

${ }^{41}$ Del deseo de familia se habla ya al comienzo de la exhortación postsinodal (AL 1), en la que se alude a la variedad de situaciones familiares (AL 52) insistiendo en dialogar con cada una, ofreciendo espacios para acompañar y escuchar sus interrogantes sobre el crecimiento en el amor, la superación de conflictos o la educación de los hijos (AL 38), sin excluir a las que participan en la vida de la Iglesia de manera imperfecta pues sobre ellas se invoca la gracia de la conversión y se les exhorta al cumplimiento del bien, a cuidar los unos de los otros y a ponerse al servicio de la comunidad (AL 78). 


\section{IDEAL DE FAMILIA Y REALIDAD FAMILIAR: HACIA UNA SUBJE- TIVIDAD INCLUSIVA}

En cuanto al primer ámbito desde el que encarar el deseado progreso en la subjetividad canónica de la familia, es necesario extraer las consecuencias jurídicas y disciplinares que derivan de la insistencia con la que el reciente magisterio exhorta a afrontar con la lucidez y el equilibrio debidos la diferencia entre el ideal de familia, que permanece como bien irrenunciable, y la realidad familiar concretamente existente, cada vez más alejada del mismo, en una variedad de situaciones y por una pluralidad de razones ${ }^{42}$. Esa lucidez y equilibrio se expresan en tres adjetivos ya conocidos y que, como una síntesis eficaz y ordenada, resumen el progreso alentado por la doctrina actual del magisterio en la materia: «acompañar, discernir e integrar». El punto de partida es el acompañamiento, tema recurrente en el magisterio del papa Francisco que lo utiliza de forma constante ${ }^{43}$, aunque su utilización en Amoris laetitia supere con creces la de los otros documentos ${ }^{44}$. Con él se expresa una actitud alejada de las tentaciones de dirigismo y de la pretensión de afrontar la realidad desde moldes preconcebidos en los que encajar personas y objetivos. Se trata pues de un proceso con el que se hace el esfuerzo de partir de la realidad concreta que se acompaña, para iluminarla en un camino hacia la madurez desde el discernimiento. Ello exige escuchar la realidad, desplazarse del centro a las periferias, practicar la cultura del encuentro sin recurrir a formularios y con disponibilidad a prestar oído, estar al lado y promover la fe y la esperanza, evitando precipitaciones a la hora de ofrecer respuestas no suficientemente cribadas

${ }^{42}$ Sueiro, 72, donde se afirma que el malestar y las quejas ante los nuevos retos de la misión enmascaran perezas y autojustificaciones estériles, recordando que al afrontar las nuevas situaciones no ha de olvidarse cuanto ya advertía K. Rhaner, esto es, que ni siquiera la Iglesia puede elegir el tiempo que le toca vivir.

${ }^{43}$ Siete veces en Lumen fidei (n. 8, 33, 35, 53, 57, 59); cinco en Laudato si' (n. 23, 105, 107, 162, 180); cuatro en Misericordiae Vultis (n. 4, 16, 23, 24); treinta y tres en Evangelii gaudium (n. 12, 24, 44, 46, 50, 69, 71, 76, 103, 169, 170, 171, 172, 173, 199, 214, 241, 285, 286); cuatro en Gaudete et exultate $(126,176)$; treinta y cuatro veces en Christus vivit (n. 12, 30, 45, 75, 92, 99, 101, 156, 170, 174, 185, 194, 203, 230, 239, 242, 243, 244, 245, 246. 247, 281, 291, 292, 297, 298); tres en Querida Amazonia (n. 14, 21, 92).

${ }_{44}$ Cincuenta y tres veces (n. 14, 16, 36, 46, 52, 60, 62, 65, 84, 93, 123, 146, 163, 185, 200, 203, 204, 207, 208, 209, 211, 216, 217, 222, 223, 230, 232, 233, 234, 242, 243 , $246,250,253,255,260,288,291,293,299,300,303,308,312)$. 
en el diálogo abierto con las personas y en la praxis de discernimiento instaurado desde el propósito de acrecentar su participación en la vida de la comunidad. Acompañar, discernir e integrar es camino obligado para romper esquemas de una evangelización autorreferencial, que termina por ser destinada solo a personas y grupos ya cercanos al ideal, apostando en su lugar por asumir la actitud de una Iglesia "en salida», que se propone hacer lo posible para que todos puedan crecer en su inserción en la comunidad como lugar de discernimiento y de participación en la experiencia de la Buena Noticia, evitando la sensación de indignidad o de exclusión que, con frecuencia, atenaza, desconcierta y paraliza a muchas personas ${ }^{45}$.

Respecto a los bienes jurídicos que se ventilan en ámbito canónico, esa tríada bien puede entenderse como la declinación de un presupuesto que debiera servir como principio guía sobre el modo de asegurar la centralidad de la familia como sujeto de derechos en el ordenamiento de la Iglesia. El principio puede formularse diciendo que «el irrenunciable anuncio del ideal de familia, hacia el que encaminar los objetivos de la acción eclesial, no puede traducirse en una disciplina arbitrariamente excluyente respecto a los bienes que merecen ser promovidos y asegurados también a realidades familiares lejanas del ideal». La subjetividad inclusiva tiene por objeto aquellos bienes jurídicos de la praxis cristiana respecto a los cuales resulta más relevante el papel de la vida de familia en sí, evitando trasladar a la realidad familiar la disciplina limitativa eventualmente aplicable a la situación de alguno de sus miembros en los sectores del munus docendi, santificandi y regend $i^{46}$.

Este presupuesto permite entender mejor la justificación de la perspectiva individual adoptada por el Código y por la misma Carta de los derechos de la familia en casi todas las cuestiones a las que se refieren sus primeros cinco artículos. En efecto, si por evitar ambigüedades se opta (como se hace en el preámbulo de la Carta) por dejar expresa constancia normativa de que por familia ha de entenderse plenamente solo

${ }^{45}$ En AL 325 se exhorta a evitar emitir juicios con dureza sobre las familias que experimentan situaciones de fragilidad.

46 Es necesario distinguir cada situación, evitando precipitaciones. Manuel Jesús Arroba Conde. "Il Vangelo dell'amore tra coscienza e norma. Aspetti giuridici". En Per una nuova cultura pastorale. Il contributo di Amoris Laetitia, dirigido por G. Autiero, 139-152. Cinisello Balsamo: San Paolo, 2019. 
la establecida según el ideal ${ }^{47}$, los derechos de los padres respecto a la educación humana y cristiana, así como respecto a la iniciación sacramental, no podrían formularse cabalmente como derechos directamente pertenecientes a la familia, por ser cada vez más frecuentes situaciones que no han desembocado formalmente en la creación de una familia correspondiente al ideal, o que han conocido una sucesiva evolución negativa hasta la disolución, formal o de hecho, del núcleo familiar; de ahí que tanto el Código (c. 226 par. 2) como la misma Carta (art. 5) ${ }^{48}$ indiquen como razón última de los derechos el hecho de haber transmitido la vida, aun cuando no se haya llegado a formar una familia, o no se haya establecido formalmente o, aunque establecida, se haya roto.

El progreso en afianzar la subjetividad canónica de la familia desde una apuesta inclusiva permitiría evitar discriminaciones no necesarias, así como la ilusoria persuasión de que a una situación familiar que resulte objetivamente regularizada, desde el punto de vista moral objetivo y en el plano jurídico, corresponda automáticamente, desde el punto de vista sustancial, una situación mejor respecto a las tareas educativas y religiosas que deben promoverse en familia ${ }^{49}$. Sobre el deseo de mayor integración en la comunidad de personas en situaciones no correspondientes al ideal familiar, el Código no prevé exclusiones directas, aunque sí indirectamente, en cuanto dicha situación está relacionada con los requisitos de «vida conforme a la fe» establecidos para determinadas funciones o servicios, como la función de padrino (c. 874, §1, 3; c. 893, §1).

${ }^{47}$ En los considerandos B y C donde se afirma, respectivamente, que «la familia está fundada sobre el matrimonio, esa unión íntima de vida, complemento entre un hombre y una mujer, que está constituida por el vínculo indisoluble del matrimonio, libremente contraído, públicamente afirmado, y que está abierta a la transmisión de la vida»; "el matrimonio es la institución natural a la que está exclusivamente confiada la misión de transmitir la vida». A ello se añade el contenido del art. 1c, donde se afirma que «la situación de las parejas no unidas por el matrimonio no debe ponerse al mismo nivel que el matrimonio debidamente contraído».

48 A ello debe añadirse el art. 4e, donde se afirma que del derecho a la protección social que asiste a los niños gozan también los hijos nacidos fuera del matrimonio.

49 Debe ofrecerse ayuda a todos «con el apoyo de psicopedagogos, médicos de familia, médicos de la comunidad, asistentes sociales, abogados de los menores y de la familia, con la apertura a recibir ayudas de la psicología, la sociología, la ciencia y el asesoramiento. Los profesionales, especialmente los que tienen experiencia en el acompañamiento, podrán encarnar propuestas pastorales en situaciones reales y en las preocupaciones concretas de las familias» (AL 204). 
Merecen pues ser revisadas algunas normas de ámbito particular que han ido añadiendo formas explícitas de exclusión no siempre justificadas, sobre todo si se comparan con el valor del testimonio que algunos de estos fieles pueden dar, precisamente por su situación, sobre ciertos aspectos de la vida cristiana. Entre estos servicios, los de naturaleza formativa pueden ser particularmente apropiados ${ }^{50}$.

En el magisterio actual hay una llamada a percatarse de los valores positivos que pudieran encerrar experiencias vividas en realidades familiares objetivamente no correspondientes al ideal, sobre todo en el terreno educativo, no quedando excluidas de ellas las potencialidades que encierra la vida en familia como escuela de inserción en la sociedad y en la Iglesia, además de como santuario de la vida. La disciplina sobre la acción pastoral no debiera resultar obstáculo para que aun en las realidades familiares frágiles se desarrolle esa triple dimensión educativa, incluido el papel de la familia como escuela de vida eclesial, porque aun cuando esté inmersa en lagunas e imperfecciones, está llamada a hacer posible que las personas crezcan en el sentido de comunión con la Iglesia y descubran su propio papel en ella como protagonistas de la misión. Como santuario de vida, toda realidad familiar está llamada en la vida cotidiana a ser lugar fructífero de transmisión de la vida y de crecimiento en las virtudes que dan forma a toda la existencia ${ }^{51}$.

\section{INTERPRETAR EN EL HORIZONTE DE LA EXPERIENCIA FAMI- LIAR EL DERECHO MATRIMONIAL}

En estrecha relación con lo que acabamos de apuntar, una segunda vía de progreso para mejor tener en consideración la subjetividad canónica de

${ }^{50}$ Más bien, fueron las disposiciones de las Conferencias Episcopales las que concretaron las disposiciones generales del Código sobre la imposibilidad de admitir a los fieles divorciados vueltos a casar para ciertas tareas. Card. Fernando Sebastián. Diez cosas que el papa Francisco quiere que sepas sobre la familia. 3. ${ }^{\mathrm{a}}$ ed. Madrid: Publicaciones Claretianas, 2016, 146-158, con una clara exposición sobre el peso de los atenuantes y sobre las posibilidades de mayor integración.

51 Cfr. Maurizio Gronchi. Chiesa Sinodo Famiglia. Città del Vaticano: Libreria Editrice Vaticana 2016, 41-52. A este propósito cabe recordar AL 200, que insta a confiar en la gracia de Dios que conduce a la Iglesia por el camino de la misericordia y hace posible nuevas vías pastorales que hagan más perceptible la acogida de toda familia y el aprecio de su tarea educativa. 
la familia, debiera consistir en interpretar los derechos formulados como bienes de las personas en clave familiar, sobre todo el derecho matrimonial $^{52}$. No se trata solo de dar impulso a la orientación ya incluida en el c. 226 §2 y a lo que se afirma en el primer considerando del Preámbulo de la Carta. En el caso del derecho matrimonial, se trata sobre todo de superar los riesgos de una interpretación de la disciplina que enfatice en demasía solo lo que se refiere al momento del consentimiento, sin atención específica suficiente a la vida de familia. En relación a ello, cabe referirse a la mejora en la presentación de esa dimensión en la preparación al matrimonio, a la necesidad de formular en modo jurídicamente más adecuado los contenidos del bonum familiae y a la improrrogable puesta a punto de la pastoral judicial, según lo ya establecido en la reforma vigente, desde el presupuesto que la revisión judicial de la validez de un matrimonio no se puede entender totalmente ajena a la exigencia de dar curso al «deseo de familia».

\subsection{La temática FaMiLIAR EN LA PREPARACión AL MATRIMONIO}

En las asambleas sinodales se trató el tema de cómo mejorar la pedagogía utilizada en la preparación al matrimonio, con propuestas muy variadas, pero prevaleciendo como criterio general la promoción de la catequesis de adultos entendida, no como actividad puntual sino como forma habitual de la vida cristiana, en la que vivir sus dimensiones esenciales (Palabra, comunidad, misión). El problema estriba en la traducción disciplinar de la deseada renovación catequética para hacer frente a la realidad que viven las parejas jóvenes de hoy (Relatio finalis, nn. 47, 59). Las normas del Código son escasas y demasiado generales: el c. 1063, 2, que se limita a establecer la preparación personal de los futuros cónyuges; el c. 1065, en el que se establece una preparación para el matrimonio con la posible recepción de otros sacramentos (confirmación, penitencia y eucaristía); los cc. 1066-1067 con disposiciones sobre la investigación que debe preceder a la celebración.

${ }_{52}$ Una línea semejante propone Juan I. Arrieta. "Il rinnovamento del sistema matrimoniale canonico alla luce dei recenti lavori sinodali". En Sistema matrimoniale canonico in Synodo, dirigido por Luigi Sabbarese, 41-59. Roma: Urbaniana University Press, 2015. 
El Pontificio Consejo para la Familia sugirió hace tiempo una disciplina más articulada, distinguiendo tres etapas de preparación: la «remota», que tiene lugar en la familia, en la escuela y en las estructuras de formación; otra "próxima», que suele consistir en cursos para los novios, en catequesis específica, en encuentros con especialistas junto a otros de carácter testimonial; y la etapa «inmediata», en la que entre los diversos objetivos, tiene especial importancia potenciar el diálogo personal con el párroco, uno de los momentos más necesitados de una disciplina más adecuada, evitando que se convierta en mera formalidad en virtud de una concepción abusiva e impropia del ius connubii que pertenece a los fieles ${ }^{53}$. Junto a ello se apuntó la necesidad de progresar en la consideración del bien de los cónyuges como finalidad esencial del matrimonio; se trata de una exigencia de naturaleza también canónica, sobre la que buena parte de la doctrina y de la jurisprudencia sigue sin sacar las consecuencias debidas, aun tratándose de una cuestión decisiva en la renovación que el Concilio Vaticano II llevó a cabo sobre la doctrina del matrimonio ${ }^{54}$. En el capítulo VI de Amoris laetitia se dedican algunos

${ }^{53}$ G. Dammacco. "La preparazione al matrimonio di fronte ai cambiamenti sociali”. En In margine al Sinodo 2014, dirigido por G. Dammacco, 129-136. Bari: Cacucci, 2014. En las asambleas sinodales se pidió asegurar una catequesis mistagógica (Relatio finalis n. 59) pero no se profundizó, como muchos hubieran deseado, en el tema de las relaciones entre fe y sacramento; se reconoció el problema que ello encierra en una sociedad cada vez más secularizada (en la que no ha de darse por supuesto que la voluntad de quien solicita el matrimonio sea la de hacer lo que hace la Iglesia), pero hubo también otras interpelaciones orientadas a evitar visiones elitistas de la praxis cristiana, olvidando que no existen instrumentos medidores de la fe. Hay muchas implicaciones jurídicas que deben ser aclaradas sobre la dignidad sacramental del matrimonio, tanto para acceder a él como para establecer su validez. Un aspecto jurídico concreto a este respecto se refiere a la admisión al matrimonio, a la luz de lo que haya podido surgir en la preparación del mismo, respecto a la situación de cada contrayente en cuanto a su contenido esencial. El código establece límites solo en caso de abandono notorio de la fe (c. 1071) y, aunque en términos exhortativos, en el caso de jóvenes condicionados en sus reales disposiciones por costumbres locales (c. 1072).

${ }^{54}$ A diferencia de la Relatio Synodi, la Relatio finalis n. 47 hace referencia explícita al concepto de bonum coniugum. En AL 233 se desarrollan sus contenidos invitando a dialogar y a estar juntos en los tiempos de crisis familiar, para favorecer la comprensión mutua y el restablecimiento de la paz en el hogar; se advierte que sin ese esfuerzo quien "era "la persona que amo" pasa a ser "quien me acompaña siempre em la vida", después solo el padre o la madre de mis hijos y al final un extraño» (AL 233). 
números a la preparación del matrimonio en los que el papa retoma las tres etapas, señaladas también en el n. 66 de Familiaris consortio, abogando por su enriquecimiento (AL 208-212); pero es en el capítulo IV, al tratar del amor, donde se expresa de forma más clara la exigencia sobre la que estamos discurriendo, esto es, la necesidad de ayudar a los futuros esposos a no entender el amor que sienten recíprocamente como un sentimiento o ideología que afecta solo a ellos, pues se trata de experiencia concreta que da origen al vínculo, cultiva los lazos que de él derivan, crea nuevas redes de integración y construye un sólido tejido social (AL 100), por lo que quien ama de veras supera el sentimiento sobre sí mismo y genera el bien de la familia, la sociedad y la Iglesia; de lo contrario, la vida familiar dejará de ser un lugar de comprensión, acompañamiento y aliento y se convertirá en un lugar de tensión permanente y de castigo mutuo (AL 108) ${ }^{55}$.

\subsection{EL CONTENIDO Y LA RELEVANCIA DEL BONUM FAMILIAE}

En la reflexión sinodal, comparando el magisterio conciliar y pontificio con las nuevas situaciones, se subrayaron como vías de desarrollo posterior ciertos valores que, en la Iglesia, pero también fuera de ella, se consideran comúnmente como bienes que dependen en gran medida de una buena experiencia de vida en la familia. Se podría pensar que estos valores y bienes son los más propiamente constitutivos del bonum familiae, es decir, los que permiten apreciar verdaderamente la familia como un bien para la persona, para la Iglesia, para la sociedad ${ }^{56}$. En la catequesis del papa Francisco sobre la familia, propuesta en las audiencias generales del periodo intersinodal, se renueva la enseñanza subrayando la dimensión predominantemente educativa que se considera confiada a la familia, no en el sentido intelectual y vertical sino en el sentido experiencial y sapiencial, que es de naturaleza circular, porque tiene como sujetos, y a la vez como destinatarios, a todos los miembros

${ }_{55}$ El cuarto capítulo trata del amor en el matrimonio y es el que más párrafos (76) y notas (72) contiene.

${ }_{56}$ En la Relatio finalis 49-51 hay elementos que permitirían formular mejor el concepto de bonum familiae. 
implicados en esa singular experiencia de amor mutuo que la familia está llamada a realizar ${ }^{57}$.

Al tratar de las causas que hoy pesan sobre la sana experiencia de la vida familiar, el camino sinodal toma en consideración la familia también en el sentido más amplio, con interés por los vínculos entre padres, hijos, abuelos, parientes, así como por el peculiar vínculo entre las dos familias de origen que teje todo matrimonio. Se advierte que, junto a los progresos con respecto a la libertad y la dignidad de las personas, ha crecido el riesgo de que estas, en términos de tiempo, calidad, dedicación e interés real, se sitúen en la familia como una isla, generando y, al mismo tiempo, experimentando en su propia carne un gran sentido de soledad y fragilidad en las relaciones. A este respecto, más que un obstáculo para la libre realización de las personas, el actual magisterio ha querido reafirmar que su mejor aliado es precisamente la calidad e intensidad de su compromiso con los lazos familiares ${ }^{58}$.

A la luz de las expectativas sociales y eclesiales sobre la familia, parece legítimo preguntarse si el contenido del bonum familiae puede reducirse a la suma del bonum coniugum y del bonum prolis, o si, por el contrario, cabe sostener su autonomía y relevancia jurídica ${ }^{59}$. Interesa dilucidar si el bonum familiae puede entenderse solo como una suma de esos dos bienes por mera acumulación o más bien como integración enriquecedora de ambos, fuente de contenidos nuevos y específicos inherentes a las condiciones que permiten a la familia cumplir su misión educativa ${ }^{60}$. Una primera razón para no excluir que la respuesta sea afirmativa se deduce del único canon en el que se menciona explícitamente el bonum familiae.

57 Para una antología sintética de la catequesis del papa sobre la familia y su misión educativa, F. Miano y G. De Simona. Famiglia. Le parole di Francesco. Roma: Ave ed., 2015.

${ }^{58}$ Cfr. Relatio finalis n. 71.

59 Sobre la base de las ideas expresadas por el juez rotal emérito, Mons. Serrano, ha habido algunos intentos de construir el concepto. Entre ellos, S. Renna. La rilevanza giuridica da attribuire al Bonum Familiae nella disciplina del matrimonio canonico. Ciudad del Vaticano: Lateran University Press, 2008. Sobre su relevancia procesal, M. J. Arroba Conde. Prova e difesa nel processo di nullità del matrimonio canonico. Temi controversi. Lugano: Eupress, 2008, 72-74.

${ }^{60}$ La orientación mayoritaria en las sentencias de la Rota Romana parece ser la de considerar las cuestiones inherentes al bonum familiae solo pertinentes a la prueba indirecta de nulidad para los demás capítulos; así se desprende de la Prolusión en la apertura del año del Estudio Rotal, en noviembre de 2014, realizada por Su Eminencia el Cardenal Lorenzo Baldisserri, Secretario General del Sínodo. 
Se trata del c. 1152 donde se establece el adulterio como título de separación y se invoca el perdón del mismo en razón del «bien de la familia». Llama la atención el criterio de redacción seguido en este canon, diverso del utilizado al regular el otro título de separación, que se formula en términos negativos: el grave peligro para la salud física y espiritual que pudiera representar mantener la convivencia; se trata de peligros para las personas del cónyuge y de los hijos, no para la familia como tal. Si la referencia expresa a la subjetividad de la familia se formula en términos de bien y para solicitar un comportamiento (el del perdón) de mayor calibre que el que correspondería en estricta justicia, es razonable pensar que esa exhortación se hace, no para sacrificar a las personas sino, por el contrario, para proteger mejor, a través de los bienes propios de la experiencia educativa en la familia, el bien común de todas ellas.

No faltan enseñanzas del magisterio que, al subrayar la dimensión educativa de la familia, apuntan en la dirección que ahora se sugiere, es decir, sin identificar el bien de la familia con los dos bienes que constituyen los fines esenciales del matrimonio. Por la lógica de los mínimos que caracteriza el fenómeno jurídico con respecto a los valores morales que lo fundamentan, sería un error establecer correspondencias automáticas entre los contenidos del bonum familiae y aquellos elementos en los que se hace consistir la consideración de la familia como un bien. El hecho de que no sea apropiado establecer correspondencias automáticas no significa, sin embargo, que pueda haber una división absoluta entre las dos cuestiones. Es pues de vital importancia en esta hora de la Iglesia y del mundo esforzarse para evitar que el bonum familiae corra la misma suerte que corrió el bonum coniugum, es decir, que siga siendo un concepto fuertemente afirmado en la catequesis y en el anuncio del Evangelio de la familia, pero resignándose a que deba transcurrir más tiempo hasta ver sobre ello una traducción canónica adecuada ${ }^{61}$. En este sentido, hay otros elementos del magisterio que ofrecen vías dignas de

${ }^{61}$ El bonum coniugum fue promovido desde los primeros padres en su predicación y en sus exhortaciones al ideal de la caritas coniugalis, pero hubo que esperar al Código de 1983 para verlo introducido con valor jurídico explícito entre los fines esenciales del matrimonio. Sobre su contenido jurídico, cf. M. Riondino. "Bonum coniugum e giuridicità nel matrimonio canonico". En Il diritto di famiglia e delle persone 38 (2009): 2048-2091; para un examen crítico de las recientes sentencias rotatorias sobre el tema, cf. C. Izzi. Il bonum coniugum nel matrimonio canonico tra incapacità consensuale e riserva invalidante, (www.diocesi.torino.it/pls/diocesitorino/V3_S2EW). 
reflexión sobre la autonomía de los contenidos del bonum familiae. Sin apartarse de la lógica de los mínimos propia del Derecho, tales elementos, aunque no encajen en la interpretación habitual del bien personal de los cónyuges o de la prole, no pueden considerarse irrelevantes para contraer un matrimonio válido.

Entre estas enseñanzas, la Gaudium et spes insiste en los deberes de cooperación entre los miembros de la familia, entendida en sentido amplio, añadiendo al tema educativo los valores de la gratitud, la confianza y el afecto, el deber de asistencia en las dificultades de la vida y en la vejez, y la apertura a otras familias; el decreto Apostolicam Actuositatem refiere este deber a la hospitalidad activa y a la promoción de la justicia hacia los necesitados, aun recordando la defensa de la legítima autonomía de la familia ${ }^{62}$. La Centessimus annus expresa como "ecología humana» aquello que hace de la familia la primera estructura donde experimentar lo que significa ser persona, permitiendo asimilar con laboriosidad la verdad, la bondad y el amor, superando el ámbito limitado de las emociones y las sensaciones individualistas ${ }^{63}$. Benedicto XVI se refirió a la familia como «comunidad de paz» (en la Jornada Mundial de la Paz 2008), en la que apreciar su «sabor genuino», ya que la familia experimenta sus componentes fundamentales, como el sentido de justicia y fraternidad, el justo sentido de la autoridad, el servicio a los más débiles, la ayuda mutua y el perdón ${ }^{64}$. El papa Francisco se refirió a la superación de la mera emocionalidad y las necesidades contingentes de la pareja en la Evangelii gaudium, donde describe a la familia como el lugar donde se aprende a vivir juntos en la diferencia y a pertenecer a los demás.

A la luz de esta doctrina, la relevancia jurídica autónoma que puedan tener los contenidos mínimos del bonum familiae para la validez del matrimonio, y no solo para su buena marcha, pueden referirse a las carencias de uno o ambos cónyuges con respecto a la cooperación y la participación activa en la vida familiar; a las actitudes o pretensiones de cerrazón absoluta de la familia en sí misma; a la mayor incidencia de esa cerrazón cuando se proyecta sobre la familia de origen propia o del otro cónyuge, especialmente en relación con el cuidado de los ancianos y los

${ }^{62}$ Gaudium et spes n. 48; Apostolicam actuositatem n. 11.

63 Juan Pablo II, Centessimus annus n. 49.

${ }^{64}$ Cfr. M. Riondino. "La famiglia nel Magistero di Benedetto XVI. Profili giuridici”. Commentarium pro religiosis 94 (2013): 229-245. 
enfermos; al umbral en el que se haya de situar el mínimo exigible al valorar comportamientos que contradicen el entorno de diálogo, confianza, gratitud y afecto que permite apreciar la propia condición de persona y progresar en su desarrollo; a las conductas antieducativas con respecto a los valores del servicio, la justicia y la paz; al peso jurídico de un autoritarismo que anule las diferencias, o de un individualismo que no permita experimentar el sentimiento de pertenencia familiar ${ }^{65}$.

\subsection{El DESEO DE FAMILIA EN LA PASTORAL JUDICIAL SOBRE LA NULIDAD MATRIMONIAL}

Sobre los procesos de nulidad, la reforma emanada por el papa Francisco en el periodo intersinodal, según lo que había surgido en la primera asamblea de 2014, redujo las intervenciones en la segunda asamblea a expresiones de agradecimiento al papa por haber acrecentado la dimensión pastoral de la actividad judicial ${ }^{66}$. Solo en una intervención se mostró cautela y se pidió examinar la aplicación de la reforma tras un quinquenio de vigencia, para corregir posibles abusos en su puesta en práctica. Las demás intervenciones sobre el tema se centraron en la necesidad de preparar a más personas, clérigos y laicos, y de garantizar la debida dedicación a este servicio, instando a los obispos a acompañar la aplicación efectiva de la reforma ${ }^{67}$.

Han pasado cinco años y no es este el lugar para análisis detallados sobre la aplicación efectiva de la reforma, pues ello exigiría adentrarse en muchos aspectos y poseer más datos de los que disponemos. Prescindiendo de los aspectos estrictamente técnicos y procesales, lo que sí parece honesto reconocer es la lentitud, o incluso la parálisis, que se registra en ciertos casos, respecto a las principales apuestas de la reforma, que miran a multiplicar este servicio especializado en favor de las situaciones de fragilidad, organizando bien la actividad preprocesal con la ayuda de otras familias, tomando más en cuenta la vida de familia en la actividad

${ }^{65}$ En la doctrina canónica más atenta no faltan aportaciones sobre estos aspectos. Carmen Peña. "Conciliación, igualdad de los esposos y corresponsabilidad parental: consecuencias jurídicas de la paridad parental en el matrimonio canónico”. Revista General de Derecho canónico y del Estado 51 (2019).

66 Francisco, Mitis Iudex Dominus Iesus per la riforma del CIC e Mitis et Misericors Iesus per la riforma del CCEO.

${ }^{67}$ Relatio finalis n. 82. 
judicial, de modo especial en la sentencia, y aprovechando las conclusiones del proceso para un deseable sucesivo acompañamiento, según lo que exige la unión entre la revisión judicial de la validez del matrimonio y la promoción del deseo de familia, desde la posibilidad de dar cabida a una nueva experiencia positiva.

Sobre la actividad preprocesal, la protección de los derechos de la familia exige poner en práctica ya, con creatividad, lo que se establece en los primeros cinco artículos de la Reglas procesales emanadas en el motu propio de la reforma, tras los cánones renovados. Se trata de asumir los elementos indicados por el papa en el preámbulo, cuando expone los motivos de esta reforma, esto es, que no se trata de multiplicar las nulidades, sino de multiplicar el servicio, por haberlo planteado de forma más ágil, de manera que pueda resultar accesible a un mayor número de fieles atribulados en su corazón por la duda, cuando no por el convencimiento de la nulidad de su matrimonio. En ese sentido, si la reforma ha mantenido la vía judicial como única vía para revisar la validez del matrimonio, es necesario entender la conversión pastoral de esta actividad no como una adulteración de su base jurídica, sino como el ofrecimiento de este servicio especializado, conjugándolo mejor en su efectiva organización con la vida y las necesidades pastorales de los fieles ${ }^{68}$.

Las normas reclaman que el servicio especializado que ofrecen los tribunales eclesiásticos revisando la validez de los matrimonios esté más presente en las parroquias, no solo porque se ofrece un servicio de información, o se orienta sobre dónde ir a buscarla, sino porque el obispo debe ofrecer al párroco la ayuda necesaria para asumir, sobre este tema, la requerida actitud «en salida», esto es, a la búsqueda de los fieles que objetivamente están en situaciones que pudieran ser objeto de la atención que ofrecen los tribunales ${ }^{69}$. Quiere ello decir que el primer ámbito

${ }^{68}$ En el preámbulo se hace referencia al frecuente desánimo de los fieles que desearían proveer a sus convencimientos de conciencia pero que perciben lejanas de ellos las estructuras judiciales. Que la actividad judicial constituya una acción pastoral especializada se puede formular como la exigencia de que el discernimiento pastoral que se ofrezca a los protagonistas de matrimonios fracasados no esté desligado del discernimiento judicial; y viceversa: que el discernimiento judicial no prescinda de la aportación especial que puede provenir del discernimiento pastoral más amplio. La actividad judicial puede enriquecer el acompañamiento a los novios en la preparación del matrimonio. Francesca Squarcia. L'amore basta? Tre domande da farsi prima del matrimonio. Roma: Città Nuova Editrice, 2020.

${ }^{69}$ Reglas Procesales art. 1. 
de la actividad preprocesal es el de la pastoral ordinaria. Esta disposición hay que completarla con las indicaciones ofrecidas en el camino sinodal, donde se señalan las familias integradas en las estructuras pastorales ordinarias como sujetos de este específico servicio pastoral, consistente en salir al encuentro de quien pudiera necesitar la ayuda del tribunal eclesiástico, sin esperar a que sean ellos los que se acerquen ${ }^{70}$.

Un segundo ámbito, relacionado con la fase de preparación de la causa, es el de la pastoral familiar, que requiere mayor coordinación a niveles supraparroquiales. Lo que no tiene sentido es que quienes trabajan en la actividad judicial no estén adecuadamente integrados en las estructuras de la pastoral familiar y, sobre todo, no es posible que en la pastoral familiar pueda descuidarse, como propuesta que debiera ser habitual, la de revisar la validez del matrimonio de quienes viven en situaciones objetivas que merecen ser revisadas a través del servicio de los tribunales ${ }^{71}$.

Sobre la incidencia de la vida de familia en la actividad judicial, además de lo que comportaría como beneficio una formulación más cabal del bonum familiae, hay que referirse al reflejo que debiera tener en la sentencia la conexión entre los objetivos de discernimiento e integración de las personas en la comunidad eclesial y la atención prioritaria que la doctrina del magisterio presta a la experiencia de vida en familia en la obra de la evangelización contemporánea. Dicho reflejo tiene que ver con las obligaciones derivadas de la sentencia, en concreto con las exhortaciones sobre posibles obligaciones naturales que haya que respetar en relación con la otra parte y la prole ${ }^{72}$ y con la cuestión del posible veto para contraer nuevas nupcias sin consultar al ordinario. En el texto de la reforma se reproducen las disposiciones del código, sin proveer con ulteriores especificaciones.

La cuestión de las obligaciones naturales es abundantemente desatendida en la praxis de los tribunales eclesiásticos de cualquier tipo e instancia. Dicha situación contrasta con el contexto hermenéutico de la reforma y

${ }^{70}$ Relatio synodi, nn. 78 e 90.

71 Reglas Procesales art. 2. En algunas diócesis se ha decidido abrir una estructura nueva, dentro de la pastoral familiar, como servicio de consulta específico para los divorciados. La primera diócesis en instituirlo ha sido la de Milán.

${ }^{72} \mathrm{La}$ necesidad de una mayor atención a las cuestiones relacionadas con la familia en los procesos de nulidad ha sido exigencia recordada sobre todo por los canonistas que estudian el tema de los intereses del menor, cfr. M. Riondino. Famiglia e minori. Temi giuridici e canonici. Città del Vaticano: Lateran University Press, 2011. 
con su inserción en el objetivo más general de plantear la evangelización partiendo de la familia. Tal objetivo exige un cambio de tendencia, que libere los pronunciamientos judiciales de la Iglesia sobre el acto del que surge el matrimonio de una intolerable abstracción, como si se pudiera prescindir del estado de vida que de hecho se estableció con el matrimonio putativo. De este surgen, en cualquier caso, responsabilidades y expectativas entre los cónyuges y la prole que, al menos en los términos exhortativos establecidos en la ley canónica, son dignos de tutela ${ }^{73}$. En el mismo sentido, resulta desconcertante la escasez de las preguntas sobre el desarrollo de la vida conyugal que suelen caracterizar los interrogatorios en las causas de nulidad, como si esta no tuviera demasiada relevancia respecto a la comprobación de la existencia de un consentimiento matrimonial adecuado y suficiente. La inversión de tendencia, además de una actividad probatoria más completa sobre estos aspectos, pasa por una mejor formación de los jueces eclesiásticos en el derecho de familia y en el derecho de menores, tanto en la perspectiva canónica como en la civil. Ello consentirá promover lo mejor posible las responsabilidades comunes y permanentes de ambos cónyuges respecto de la educación integral (también religiosa) de la prole, así como el compromiso de cada uno de ellos (tal vez diversificado) en garantizar su digno sustento material. Debiera merecer la atención de todo el colegio, sin dejar el tema solo para el ponente, todo lo que se refiere al modo de indicar en la sentencia los aspectos que puedan prestarse, en la jurisdicción civil, a instrumentalizaciones que comprometerían aún más las comunes responsabilidades como padres, como ocurre con los temas relacionados con la incapacidad psíquica matrimonial ${ }^{74}$.

${ }^{73}$ El problema se da donde hay acuerdos entre la Iglesia y el Estado que prevén la transcripción civil de la sentencia canónica si ello, además de la nulidad, implica la anulación de otras medidas de compensación económica establecidas en la separación. Debiera estudiarse la posibilidad de establecer en la sentencia canónica la prohibición de hacerla valer civilmente para esos efectos, si provocan injusticia para la parte más débil que no tenga responsabilidad en la nulidad.

${ }^{74}$ Debe procederse con sumo cuidado a la hora de referirse en la sentencia a la incapacidad matrimonial de una de las partes, explicando con precisión su significado estrictamente canónico respecto a la validez del consentimiento, de forma que el haberla comprobado para ese fin no se preste a sucesivas a manipulaciones que pongan en entredicho también, sin el debido fundamento, la capacidad genitorial, comprometiendo con ello la tutela del interés superior del menor, que en general conlleva garantizar su relación con ambos padres. Sobre el significado del concepto 
El veto de pasar a nuevas nupcias hay que evitar imponerlo con una ligereza aún menos justificada en el contexto de la reforma ${ }^{75}$. Excepto en los dos casos en los que el motivo de nulidad comprobado comporta la nulidad de cualquier otro futuro matrimonio ${ }^{76}$, la Dignitas Connubii remite a la prudencia de los jueces valorar la necesidad o conveniencia de imponer el veto, evitando por tanto el excesivo automatismo en hacerlo que se manifiesta en la praxis de la mayoría de tribunales ${ }^{77}$. El renovado valor de la celeridad, que ha marcado la obra de la reforma, se suma a la exigencia de actuar con cautela en este tema, según los datos precisos recogidos en cada caso, y sin unir automáticamente el tema del veto al capítulo de nulidad comprobado.

No ha sido objeto expreso de disposiciones en la reforma procesal el tema de la ayuda a los cónyuges tras la conclusión de la causa. Vista la exigencia de exponer adecuadamente las motivaciones, cabe esperar que la decisión pueda ser comprendida en conciencia por los destinatarios ${ }^{78}$. Al servicio de información, consejo y mediación ${ }^{79}$, así como a abogados que actúen según una correcta deontología canónica, se podría encomendar la tarea de ofrecer la ayuda necesaria para comprender la decisión, espe-

de supremo interés del menor, M. Riondino. "L'evoluzione del concetto di interesse del minore nella cultura giuridica europea”. Civitas et Iustitia 6 (2008): 389-411. En AL 245 se advierte de la herida difícil de curar que provoca en los hijos la estrategia de querer conquistar su afecto usando como técnica la demolición de la imagen del otro progenitor, para defenderse o vengarse.

75 El desafío pastoral que refleja el concepto del «deseo de familia» sugiere no descartar que pueda entenderse también como posible manifestación del mismo la decisión de poner fin a una experiencia conyugal negativa y, por consiguiente, de emprender otra nueva experiencia familiar más acorde con ese deseo que, desde la fe, entendemos sembrado por el Creador en el corazón de toda persona; M. J. Arroba Conde. "Aspectos pastorales de la reciente reforma procesal". Commentarium pro Religiosis et Missionariis 97 (2016): 67-103.25-26. La decisión de imponer veto para contraer nuevas nupcias no puede ser ajena a este renovado objetivo de la reforma, consistente en facilitar (sin cargas de tiempo no necesarias), una nueva experiencia de vida en familia.

${ }^{76}$ Esto es, en los casos de impotencia absoluta y de incapacidad psíquica permanente.

77 M. J. Arroba Conde. "Incidencias de la reforma procesal en la sentencia". Anuario Argentino de derecho canónico 23 (2017): 57-77.

${ }_{78}$ Este objetivo exige mejorar la técnica de motivación de las sentencias, M. J. Arroba Conde. Risultato della prova e tecnica motivazionale nelle cause matrimoniali. Casi pratici di prima istanza. Città del Vaticano: Lateran University Press, 2013, 7-8.

79 Relatio finalis n. 82. 
cialmente al cónyuge que ha mantenido en el juicio una postura contraria al resultado establecido, sin excluir la información sobre el derecho de impugnación y sobre cómo presentar de manera más adecuada aquellos aspectos de su visión que no se consideraron suficientes.

En las causas concluidas sin la certeza requerida sobre la nulidad del matrimonio, la sentencia debe dejar constancia, si los hubiera, de hechos moralmente ciertos que pudieran justificar formalmente, incluso coram Ecclesia, la separación de los cónyuges. En su catequesis el papa Francisco llegó a decir que la separación, en ciertos casos, es un deber moral ${ }^{80}$. El derecho canónico prevé esta situación en estrecha relación con las garantías sobre el mantenimiento del bonum familiae (c. 1152). Una decisión canónica tendría como principal ventaja rescatar la cuestión del mero juicio subjetivo de los fieles o de las medidas establecidas en la jurisdicción civil, comprensiblemente incompletas sobre ciertos elementos importantes de naturaleza relacional y educativa; en la decisión canónica se debe establecer cuanto pueda favorecer la debida armonía entre los cónyuges separados en virtud del interés superior de los hijos, incluida su educación religiosa ${ }^{81}$.

Lo que se desprende de la sentencia, aunque haya resultado insuficiente para constatar la nulidad del matrimonio, puede ofrecer motivos razonablemente objetivos para un mayor discernimiento por parte de los fieles sobre el fracaso de su matrimonio, permitiéndoles concentrarse en los puntos principales en los que hacer el arrepentimiento necesario y centrar la reparación necesaria, contando con el acompañamiento de la Iglesia, en cuya vida los fieles están llamados a participar. En este contexto, el obispo, con la ayuda de la penitenciaría, sobre la base de los resultados del proceso judicial, puede establecer un camino específico de penitencia para los fieles involucrados en nuevas uniones de las que han surgido nuevas obligaciones familiares naturales. El referido camino penitencial debe permitir a estos fieles tener una experiencia efectiva del Evangelio de la familia, apreciando la verdad que en él se encierra, pero también haciendo posible experimentarlo en cuanto buena noticia

${ }^{80}$ En esta línea debe entenderse la necesidad de distinguir bien las distintas situaciones de fracaso y ruptura de la unión conyugal, retomando el criterio expresado por San Juan Pablo II en la Familiaris Consortio n. 84; Relatio finalis n. 85.

81 Cfr. A. Ingoglia. La separazione coniugale nel diritto canonico. Milano: Giuffré, 2004, 2-22. 
de la misericordia de Dios que surge en su encuentro con el hombre pecador $^{82}$.

\section{INTEGRACIÓN DE LA DISCIPLINA SOBRE ALGUNOS ELEMENTOS}

Respecto a la conveniencia de completar con adecuada disciplina algunos aspectos relacionados con la protección de la atención que merece la familia en la acción pastoral y con la promoción más eficaz de su papel, tanto en la Iglesia como en la sociedad, conviene aclarar que no se trata de depositar la confianza en nuevas normas o reglamentaciones, sino de evitar negligencias o dejar al puro arbitrio de los distintos estamentos responsables de la pastoral familiar, la aplicación de Amoris laetitia como doctrina que exige una nueva cultura en la acción evangelizadora. Se trata pues de asegurar las claves ofrecidas en dicho magisterio papal y sinodal, para acompañar hacia el ideal evangélico de familia toda situación familiar, incluida la de las familias que, aunque establecidas con regularidad desde el punto de vista jurídico, necesitan mejorar su experiencia para sostenerla como una buena experiencia de Iglesia doméstica.

De esa condición deriva la necesidad de promover nuevas vías pastorales en el área de la formación y de la catequesis familiar, en la espiritualidad conyugal y familiar y en la atención personalizada a la realidad de cada familia, otorgando la prioridad a estas exigencias en los planes de cada estructura o sector pastoral ${ }^{83}$. Mención expresa merece el acompañamiento durante los primeros años de la vida conyugal; en el camino sinodal se pidió un desarrollo ulterior a nivel parroquial, diocesano y de la conferencia episcopal (Relatio finalis n. 60); en Amoris laetitia se advierte que los primeros años de la vida matrimonial son una escuela para madurar, en la que se aprende y se reconoce el sentido del bien de la familia (AL 220), por lo que se recomienda que las nuevas parejas sean asistidas por parejas experimentadas, con las que compartir los principales retos de la vida familiar, como la paternidad y la maternidad. Los

${ }^{82}$ Cfr. Relatio finalis n. 86.

${ }^{83}$ Se trata de entender el papel que juega la familia en la «sociedad de los cuidados» de manera que pueda ser considerada realidad transversal desde la que organizar los varios sectores de la pastoral (educativa, sanitaria, caritativa, etc.) o, al menos, de la que no se prescinda en ningún sector. Fernando Vidal Fernández. El valor de la familia en la sociedad de los cuidados. Madrid: UPC, 2016. 
pastores deben alentar a la familia a vivir en la fe con la práctica constante de la reconciliación, la participación en retiros, la oración en familia y la participación en la vida de la comunidad (AL 227). Por consiguiente, hay que considerar que los primeros años después del matrimonio constituyen una etapa de atención pastoral digna de explícita protección disciplinar, en términos similares a los establecidos en el código sobre las primeras etapas después de la profesión religiosa (c. 659; sobre los cónyuges, cc. 1063, 4 y 1064).

En el reciente magisterio se señalan otros ámbitos dignos de más protección canónica y que amplían la subjetividad de la familia, configurando mejor su responsabilidad ministerial fuera del hogar. Su ministerio más específico es proclamar la belleza de la familia, es decir, promover y apoyar, a nivel especialmente testimonial, la calidad de las relaciones interpersonales entre los cónyuges, entre los padres y los hijos, entre las familias (Relatio finalis nn. 1 e 51); la protección de las familias más débiles; la cercanía a los que viven en circunstancias de especial sufrimiento; la acogida de las familias en dificultad; el estímulo a los que dudan en comprometerse con confianza; y el acompañamiento adecuado de los que han experimentado el fracaso de la unión familiar (Relatio finalis, nn. 77, 83). A este respecto, el camino sinodal ha valorado el papel de los movimientos y asociaciones familiares. Cabe pues afirmar que el progreso en la subjetividad canónica de la familia incluye entre sus principales elementos el fenómeno de las asociaciones familiares, alentado por el magisterio pontificio y expresamente formulado en la Carta de los Derechos de la Familia (art. 8, letra b), tanto en lo que se refiere a su presencia en la sociedad y en las instituciones públicas, como en lo que se refiere a la contribución ministerial específica de la familia, valorizada ya en el anterior sínodo sobre este tema (Familiaris Consortio 46; 72).

Entre las cuestiones que más cabe relacionar con la promoción de los movimientos y las asociaciones familiares en la Iglesia ocupa un lugar destacado todo aquello que pueda favorecer el afianzamiento de lo que podría denominarse «derecho de la familia», relacionado con el sector público y no con las relaciones pertenecientes al derecho privado, como ocurre en el «derecho de familia». Su objeto son las políticas sociales y económicas que tienen fuerte impacto en la vida familiar; las relacionadas con la atención a los más débiles: los menores, los ancianos, los enfermos; otras que pueden calificarse de situaciones extremas. El derecho público 
de la familia debiera ser considerado como parámetro para evaluar hasta qué punto son adecuadas las normas de otras áreas del derecho: fiscal, sanitario, laboral, escolar, las que tratan de la ayuda a las personas que cuidan de personas dependientes... El impacto existencial de cada una de las mencionadas legislaciones sectoriales sobre la estabilidad y la unidad de la familia podría convertirse en un criterio e instancia crítica, en consonancia con el objetivo de permitir que la familia desempeñe su papel insustituible como capital social ${ }^{84}$.

Entre las actividades pastorales encaminadas a proteger el papel de la familia en la sociedad hay una urgencia sobre la que no deben ahorrarse esfuerzos, de manera que no se interprete de forma errada el planteamiento inclusivo de la subjetividad canónica propuesto anteriormente como primer camino para el progreso en ella. El actual pluralismo legislativo insta a no descuidar en el terreno formativo y asociativo el desfase entre ciertas iniciativas legislativas en materia de familia y la enseñanza cristiana sobre el único ideal de la familia, fundada en el matrimonio entre hombres y mujeres ${ }^{85}$. En tal sentido, la reflexión sobre las llamadas «leyes imperfectas» parece necesaria para orientar mejor a los fieles, de manera similar a lo que se ha hecho en relación con las cuestiones

${ }^{84}$ Como puede apreciarse, esta cuestión está en continuidad con la Carta de los Derechos de la Familia, que en el camino sinodal se pidió retomar, en cuanto aún permanecen en su urgencia los objetivos de la misma, esto es, hacer un «llamamiento profético en favor de la institución familiar» y proponer una "guía para la elaboración de legislación sobre la familia» que incluya los derechos de la familia a un nivel de vida digno, a una organización del trabajo que no favorezca la disgregación, a una vivienda decente y a la reunificación, en el caso de familias de migrantes (Relatio Finalis n. 92). Para ello es necesario utilizar instrumentos empíricos lúcidos, sin conformarse con aquellas iniciativas indispensables, pero claramente insuficientes, basadas únicamente en la buena voluntad. Se requiere una mayor competencia jurídica, apoyada por análisis interdisciplinares adecuados de la realidad familiar. Solo de análisis fiables pueden surgir estrategias legislativas verdaderamente útiles. La promoción de una legislación familiar adecuada debe ir acompañada de otro tipo de estrategias, incluidas las iniciativas educativas y de prevención, junto con una presencia operativa directa.

${ }^{85}$ Las únicas huellas de este tema en la Relatio finalis son los nn. 76 y 92; el primero, para referirse al abuso «inaceptable» que representa el hecho de que los organismos internacionales condicionan la ayuda a los países pobres a la introducción de leyes que establezcan el matrimonio entre personas del mismo sexo; el segundo, para indicar la necesidad de alentar a los laicos y a las asociaciones familiares que se dedican a cuestiones culturales y sociopolíticas. 
pertenecientes a la relación entre bioética y derecho ${ }^{86}$. El acercamiento pastoral sin discriminaciones a las realidades familiares, así como el reconocimiento de elementos positivos presentes en situaciones alejadas del ideal de la familia, no zanjan del todo la cuestión del significado jurídico de las uniones afectivas no matrimoniales ${ }^{87}$. Hoy en día hay muchas más situaciones en las que se produce este tipo de unión, incluyendo parejas de hecho entre una mujer y un hombre y, aunque en mucho menor número, parejas homosexuales ${ }^{88}$. Lo que interesa señalar ahora es que la existencia de valores y contravalores en esas situaciones no es irrelevante desde el punto de vista jurídico. Tanto formalizando la relación de hecho como complementando con medidas legislativas específicas las normas que ya dan cierta importancia a las relaciones de hecho, los objetivos que ahora pesan sobre los sistemas legales de muchos países se remontan a la necesidad de especificar las consecuencias jurídicas que derivan de la existencia de esas relaciones, especialmente en lo que respecta a los deberes que promanan de ellas, así como indicar los límites dentro de los

${ }^{86}$ Cf. Juan Pablo II, Evangelium vitae, n. 73. Según una categoría ya muy difundida en la teología moral, las «leyes imperfectas» plantean la cuestión de los criterios en base a los cuales se está llamado a influir en la actividad legislativa en los contextos democrático-pluralistas, cuando se considera que no permiten regulaciones exentas de censura ética.

87 El Sínodo ha querido utilizar un lenguaje que parte de los elementos positivos presentes en las situaciones imperfectas (Relatio finalis n. 70) aunque muchos Padres subrayaron la diferencia entre la positividad que existe en las personas protagonistas de tales relaciones afectivas imperfectas y la dudosa positividad objetiva de la propia situación imperfecta, distinguiendo en todo caso entre las uniones de hecho y las uniones matrimoniales (Ib., n. 71). La tipología de las parejas de hecho entre una mujer y un hombre es muy variada: algunos excluyen la unión conyugal porque no le atribuyen valor a dicha institución; otros no tienen la intención de asumir los deberes legales relacionados con el matrimonio y la hipotética disolución del vínculo; otros no quieren que su cohabitación tenga carácter de estabilidad; otros quieren o no excluyen la unión conyugal en el futuro; otros establecen la cohabitación por razones de ayuda mutua en la vejez.

${ }^{88}$ Cf. Relatio Synodi nn. 23-28; Relatio finalis nn. 69-86. El respeto de la exigencia moral se confía a la conciencia de cada individuo, mientras que la cuestión de las leyes imperfectas se refiere al problema del contenido de la norma jurídica que la autoridad pública puede llegar a imponer coercitivamente, con los límites correspondientes. Así, por ejemplo, de la afirmación de que el matrimonio es el contexto moral propio de la generación de hijos, no se deduce que sea posible prohibir por ley la procreación fuera del matrimonio. Este tipo de argumentación es el que subyace a la propuesta de profundizar el tema de las leyes imperfectas en materia matrimonial. 
cuales pueden considerarse válidos los acuerdos contractuales entre las partes interesadas ${ }^{89}$.

Sobre el significado jurídico de estas situaciones ${ }^{90}$, cabe señalar dos conceptos rectores especialmente urgentes: la protección del matrimonio y el interés supremo del niño como criterio para la legislación en materia de adopción. El matrimonio tiene un valor específico desde el punto de vista humano y en la comunidad civil, independientemente de opciones de fe, por lo que todo lo que ayude a los jóvenes a contraer matrimonio y fundar una familia debe ser objeto de preocupación legislativa, especialmente en lo que respecta a la posibilidad de tener un trabajo estable; además, la asunción pública de las cargas y compromisos que implica el matrimonio debiera ser reconocida legalmente en formas específicas de incentivo o ayuda ${ }^{91}$.

El concepto de interés superior del niño está recogido en las convenciones internacionales sobre los derechos del niño; en el ámbito del derecho de familia es un elemento que afecta a las leyes que rigen los aspectos vinculados al derecho a la educación y al bienestar integral, especialmente en los casos de separación de los padres. Si bien la evolución de las leyes sobre estos aspectos es sustancialmente positiva en la mayoría de los sistemas y coherente con la protección suprema del interés del niño, no faltan proyectos en el ámbito de la adopción en los que esta

${ }^{89}$ Estos objetivos no siempre se refieren a los vínculos homosexuales, sobre los que la legislación de muchos países no prevé la formalización legal. Sería excesivo además sostener que la mayoría de parejas homosexuales quieran formalizar su relación para asumir obligaciones específicas; la reivindicación de su formalización parece perseguir más bien una acreditación ético-social. Sobre este punto el Sínodo se ha expresado en la Relatio finalis n. 76.

${ }_{90}$ El tema recuerda el discernimiento hecho en el Sínodo sobre la relación entre la Verdad del Evangelio de la familia y la Misericordia con la que hay que proclamarla especialmente en situaciones complejas alejadas del ideal evangélico.

91 De ahí que las familias cristianas deban promover acciones orientadas a contrarrestar las iniciativas legislativas que ya no identifican el matrimonio como una institución con un derecho propio desde el punto de vista jurídico, entendido como pacto relacional para la vida entre una mujer y un hombre; esta institución ha demostrado ser piedra angular de la sociedad. Del respeto a otras formas de relación y del reconocimiento de los valores positivos que pueden expresarse en ellas, no se desprende en absoluto que sea jurídicamente apropiado asimilar a la familia, fundada en el matrimonio, otras formas de relaciones afectivas entre dos personas; se trata de situaciones identificadas por vínculos con características distintas del matrimonio, por lo que la asimilación no se correspondería con la realidad. 
protección parece ser más cuestionable ${ }^{92}$. La temática está muy vinculada al problema del menor apoyo social que hoy en día posee la idea de que la generación de los hijos es un acto humano que expresa la relación entre una mujer y un hombre, como padres del niño; es bien sabida la expansión de una concepción de la generación como un hecho meramente técnico, consistente en la fecundación entre un gameto femenino y uno masculino de cualquier origen, que puede llevarse a cabo a petición de cualquiera que desee tenerlo.

Como ocurre sobre el matrimonio, también sobre la cuestión del contexto relacional y humanizador de la procreación, nos encontramos ante un tema no directamente religioso, sino constitutivo de un nudo cultural ineludible ante las posibilidades cada vez mayores de gestión puramente técnica del momento generativo, así como ante el deseo generalizado de dar respaldo legislativo a la idea de que la identidad masculina o femenina dependería de la elección discrecional de cada individuo ${ }^{93}$.

El elemento más digno de reflexión, desde un punto de vista jurídico, deriva del hecho de que tener por objeto directo o indirecto situaciones imperfectas no convierte automáticamente en imperfecta, en sentido moral, toda norma relacionada con ellas, porque puede haber perfiles de la intervención normativa sobre situaciones imperfectas que podrían considerarse obligatorios también desde un punto de vista moral ${ }^{94}$. En este sentido, parece necesario asegurar que las leyes, cuando su plena correspondencia con la exigencia moral no sea practicable, sean las mejores posibles en la práctica, evitando así un mal mayor. No se trata, pues, de admitir excepciones a la acción moral sino, por el contrario, de identificar la acción moralmente apropiada (la mejor posible) en situaciones refractarias a opciones irreprochables desde el punto de vista ético. Esto plantea sin duda graves problemas de discernimiento, especialmente

92 El Sínodo se ocupó de la adopción y de la custodia en la Relatio finalis n. 65.

93 Los aspectos negativos del llamado "genderismo» se mencionan en la Relatio finalis n. 33. Sobre ciertos aspectos jurídicos vinculados al contexto relacional de la generación humana, L. Eusebi. "Se il desiderio del figlio diventa diritto". Lemà Sabactani. Contributi per una cultura dell'adozione 15 (2015): 25-34.

${ }_{94}$ Pensemos en la disolución de una convivencia more uxorio prolongada de hecho por mucho tiempo; no sería ni legal ni moralmente aceptable que el miembro de la pareja titular de una renta o de un patrimonio esté exento por ley de toda responsabilidad hacia el otro, si el mismo, por la desaparición de la convivencia, se encuentra en situación de necesidad. 
para determinar las prioridades que deben salvaguardarse con respecto a los aspectos de menor alcance, así como los umbrales que no deben traspasarse ${ }^{95}$.

\section{CONCLUSIONES}

El resultado de la reflexión presentada puede sintetizarse afirmando la exigencia de acrecentar la consideración de la familia, en sí misma, como sujeto de derechos y deberes en la Iglesia, superando los márgenes de las normas codificadas interpretándolas a la luz del reciente magisterio, que permite además completar sus lagunas en vistas a tutelar mejor la atención que merece la familia como ámbito imprescindible de la evangelización y a proteger su ministerio específico en la comunidad eclesial y en toda la sociedad.

Esa aproximación al tema ha consentido proponer tres ámbitos de progreso en la consideración de la subjetividad canónica de la familia que derivan de la constante invitación del magisterio actual a encarar adecuadamente la relación entre el ideal de familia, que se debe siempre proclamar, y las realidades familiares efectivamente existentes. El primer ámbito es el de encarar las diferencias entre ideal y realidad desde una subjetividad inclusiva; el segundo ámbito consiste en interpretar los derechos reconocidos a las personas en materia familiar, especialmente el derecho matrimonial, desde lo que exige una mayor inserción de los mismos en el horizonte de una buena experiencia familiar; el tercer ámbito pasa por la conveniencia de recurrir a instrumentos disciplinares ágiles, de forma que el reciente magisterio sobre la familia, especialmente la

${ }^{95}$ Luciano Eusebi (cur.). Il problema delle leggi imperfette. Etica della partecipazione all'attività legislativa in democracia. Brescia: Morcellania, 2017. Cruzar ciertos umbrales en las normas no permite encontrar en ellas un bien que pueda ser razonablemente perseguido, por lo que asentir en ellas se convertiría en un antitestimonio, dado el valor pedagógico de las leyes sobre las costumbres. Es cierto, sin embargo, que el mero testimonio para obtener una legislación plenamente conforme a los principios morales puede no ser la mejor estrategia moral si conduce a perderlo todo, a perder las conquistas parciales presentes en las leyes propuestas que, aunque imperfectas, representan una mejora desde el punto de vista ético con respecto a la situación, ya sea la de la ley existente o la de la ley que se pretende emanar si está aún más lejos del ideal. Se puede pensar que existe un deber moral de colaborar en la introducción de leyes menos imperfectas. 
perspectiva propuesta en Amoris laetitia, no quede sin fecunda aplicación $\mathrm{o}$, incluso, termine por ser bloqueado arbitrariamente.

\section{REFERENCIAS}

Akhtar R. C. \& C. Nyamutata. International Child Law. London and New York: Routledge, 2020.

Arrieta, Juan Ignacio. "Il rinnovamento del sistema matrimoniale canonico alla luce dei recenti lavori sinodali". En Sistema matrimoniale canonico in Synodo, dirigida por Luigi Sabbarese, 41-59. Roma: Urbaniana University Press, 2015.

Arroba Conde, Manuel Jesús. "Il Vangelo dell'amore tra coscienza e norma. Aspetti giuridici". En Per una nuova cultura pastorale. Il contributo di Amoris Laetitia, dirigida por G. Autiero, 139-152. Cinisello Balsamo: San Paolo, 2019.

Arroba Conde, Manuel Jesús. "Missione ecclesiale e pastorale giudiziale". Apollinaris 91 (2018): 405-426.

Arroba Conde, Manuel Jesús. "Incidencias de la reforma procesal en la sentencia". Anuario Argentino de derecho canónico 23 (2017): 57-77.

Arroba Conde, Manuel Jesús. "Il metodo dell'utrumque ius". Apollinaris 90 (2017): 265-272.

Arroba Conde, Manuel Jesús. "Aspectos pastorales de la reciente reforma procesal”. Commentarium pro Religiosis et Missionariis 97 (2016): 67-103.25-26.

Arroba Conde, Manuel Jesús. "La recente esperienza sinodale in prospettiva canonica". Commentarium pro Religiosis et Missionariis 96 (2015): 263-286.

Arroba Conde, Manuel Jesús. Risultato della prova e tecnica motivazionale nelle cause matrimoniali. Casi pratici di prima istanza. Città del Vaticano: Lateran University Press, 2013.

Arroba Conde, Manuel Jesús. Prova e difesa nel processo di nullità del matrimonio canonico. Temi controversi. Lugano: Eupress, 2008.

Arroba Conde, Manuel Jesús. "Basi ecclesiologiche e limiti intrinseci di una rinnovata produzione normativa locale". Folia Canonica 10 (2007): 153-166.

Arroba Conde, Manuel Jesús y Michele Riondino. Introduzione al Diritto canonico. 3. ${ }^{\mathrm{a}} \mathrm{ed}$. Milano: Mondadori Education, 2019. 
Ballarani, G. "Nascituro (soggettività del). En Enciclopedia de la bioética e scienza giuridica, dirigida por Sgreccia y Tarantino, vol. IX, 136-ss. Napoli: E.S.I., 2015.

Cerdá Donat, M. T. "Educación católica y sociedad civil". Anuario de Derecho Canónico 5 (2016): 165-187.

Dammacco, G. "La preparazione al matrimonio di fronte ai cambiamenti sociali”. En In margine al Sinodo 2014, dirigida por G. Dammacco, 129-136. Bari: Cacucci, 2014.

De Angelis, F. L'educazione del minore e la libertà religiosa. Città del Vaticano: Lateran University Press, 2018.

Degiorgi, G. I minori nella legislazione della Chiesa. Venezia: Marcianum Press, 2015.

Eusebi, L. (cur.). Il problema delle leggi imperfette. Etica della partecipazione all'attività legislativa in democracia. Brescia: Morcellania, 2017.

Eusebi, L. "Se il desiderio del figlio diventa diritto". Lemà Sabactani. Contributi per una cultura dell'adozione 15 (2015): 25-34.

García Vilardell, M. R. "La libertad de creencias del menor y las potestades educativas paternas: la cuestión del derecho de los padres a la formación religiosa y moral de sus hijos". Revista española de derecho canónico 66 (2009): 331-351.

Gherri, Paolo (ed.). Diritto canonico e pastorale: la norma missionis. Città del Vaticano: Lateran University Press, 2020.

Gherri, Paolo. "Identità ecclesiale e Norma Missionis". Apollinaris 91 (2018): 505-544.

Gronchi, Maurizio. Chiesa Sinodo Famiglia. Città del Vaticano: Libreria Editrice Vaticana, 2016.

Ingoglia, A. La separazione coniugale nel diritto canonico. Milano: Giuffré, 2004.

Izzi, C. Il bonum coniugum nel matrimonio canonico tra incapacità consensuale e riserva invalidante. Consultado el 26 de agosto de $2020 \mathrm{http}: / /$ www.diocesi.torino.it/pls/diocesitorino/V3_S2EW

Martin, D. "La Carta dei diritti della Famiglia; le sue origini e la sua originalità". En La famiglia e i suoi diritti nella comunità civile e religiosa, 99-107. Roma: Libreria Editrice Vaticana - Libreria Editrice Lateranense, 1987.

Miano, F. y G. De Simone. Famiglia. Le parole di Francesco. Roma: Ave ed., 2015.

Miele, M. "Educazione religiosa del minore". En Scuola, Famiglia e Minori, dirigida por M. Cerato y F. Turlon, 401-425. Pisa: Pacini Giuridica, 2018. 
Osoro, Carlos. La familia, Iglesia doméstica. Una propuesta pastoral. 2. ${ }^{\text {a }}$ ed. Madrid: PPC, 2019.

Peña, Carmen. "Conciliación, igualdad de los esposos y corresponsabilidad parental: consecuencias jurídicas de la paridad parental en el matrimonio canónico". Revista General de Derecho canónico y del Estado 51 (2019): 1-23.

Renna, S. La rilevanza giuridica da attribuire al Bonum Familiae nella disciplina del matrimonio canonico. Città del Vaticano: Lateran University Press, 2008.

Riondino, Michele. "The right to education: a fundamental and universal right”. Jus 63 (2016): 287-300.

Riondino, Michele. "La tutela dei minori nell'ordinamento canonico". En La Chiesa tra economia e famiglia, dirigida por G. Dammacco, 181-193. Bari: Cacucci, 2015.

Riondino, Michele. "La famiglia nel Magistero di Benedetto XVI. Profili giuridici”. Commentarium pro religiosis 94 (2013): 229-245.

Riondino Michele. "Linteresse del minore come legittimazione e limite dell'ordinamento in materia religiosa". En Legittimazione e limiti degli ordinamenti giuridici, dirigida por G. L. Falchi y A. Iaccarino, 623-633. Città del Vaticano: Lateran University Press, 2012.

Riondino, Michele. Famiglia e minori. Temi giuridici e canonici. Città del Vaticano: Lateran University Press, 2011.

Riondino, Michele. "Bonum coniugum e giuridicità nel matrimonio canonico". Il diritto di famiglia e delle persone 38 (2009): 2048-2091.

Riondino, Michele. "L'evoluzione del concetto di interesse del minore nella cultura giuridica europea". Civitas et Iustitia 6 (2008): 389-411.

Sebastián, Fernando. Diez cosas que el papa Francisco quiere que sepas sobre la familia. 3. ${ }^{\mathrm{a}}$ ed. Madrid: Publicaciones Claretianas, 2016.

Squarcia, F. L'amore basta? Tre domande da farsi prima del matrimonio. Roma: Città Nuova Editrice, 2020.

Sueiro, Samuel. "Espiritualidad para la misión”. Estudios Eclesiásticos 95 (2020): 69-111. DOI: https://doi.org/10.14422/ee.v95.i372.y2020.003

Verhellen, E. Convention on the Rights of the Child. Background, motivations, strategies, main themes. $4^{\text {th }}$ ed. Antwerpen: Garant, 2006.

Vidal Fernández, Fernando. El valor de la familia en la sociedad de los cuidados. Madrid: Universidad Pontificia Comillas, 2016.

Vitali, E. "Riflessioni sui rapporti familiari nell'esperienza giuridica ecclesiale”. Il Diritto ecclesiastico 116 (2005): 409-430. 